\title{
Recent Topics on the Structure and Crystallization of Al-based Glassy Alloys
}

\author{
Cang Fan ${ }^{a}{ }^{\oplus}$, Xingxing Yue ${ }^{a}$, Akihisa Inoue ${ }^{b, c}$, Chain-Tsuan Liu ${ }^{d}$, Xiaoping Shen ${ }^{a}$, Peter K. Liaw \\ ${ }^{a}$ Nanjing University of Science \& Technology, Nanjing 210094, P.R, China \\ ${ }^{b}$ International Institute of Green Materials, Josai International University, Togane 283-8555, Japan \\ ${ }^{c}$ Department of Physics, King Abdulaziz University, Jeddah 22254, Saudi Arabia \\ ${ }^{d}$ Department of Mechanical and Biomedical Engineering, City University of Hong Kong, Hong Kong, \\ P.R, China \\ ${ }^{e}$ University of Tennessee, Knoxville 37996, USA
}

Received: September 13, 2018; Accepted: November 16, 2018

\begin{abstract}
Al-based glassy alloys (metallic glasses) have been of great scientific and technological interest as a high specific strength and high corrosion resistant materials. However, the low glass-forming ability (GFA) is still a choke point that greatly influences the applications. In order to further comprehend the glass formation mechanism and investigate the possibility of enhancing the GFA, it is important to obtain the definite information on the atomic scale glassy structures in correlation with properties and to study the composition dependence of crystallization and properties of Al-based metallic glasses. The purpose of this paper is to summarize the structure characteristics and crystallization behavior in conjunction with alloy component in Al-based metallic glasses and to investigate the possibility of synthesizing an Al-based bulk metallic glass with better engineering performances. This may assist to learn the structural features systematically and understand the development and current status for Al-based metallic glasses.
\end{abstract}

Keywords: Al-based metallic glasses, Glass-forming ability, Structural characteristics, Crystallization.

\section{Introduction}

Metallic glasses have been intensively investigated in conjunction with the developments of various meltquenched techniques. The first synthesis of a glassy alloy in Au-Si system by rapid quenching form melt was made by Klement et al. in $1960^{1}$. Since then, much attention has been paid to metallic glasses and a great large number of studies have been carried out to date. Nowadays, metallic glasses can be produced in a variety of alloy systems. These glassy alloys exhibit excellent characteristics such as high mechanical strength ${ }^{2-4}$ and good corrosion resistance ${ }^{5-8}$ due to the absences of long-range periodic atomic order and grain boundary. Tremendous effort has been devoted to pursue the bigger size of bulk metallic glasses (BMGs) ${ }^{9}$ that are referred to the glassy alloys whose dimension is over $1 \mathrm{~mm}^{10}$. BMGs have attracted a definitely increasing interest because of their formation in engineering alloy systems such as $\mathrm{Mg}^{11-12}, \mathrm{Zr}^{13-16}, \mathrm{Ti}^{-17-19}$ and Fe-based ${ }^{20-22}$. At present, the world's biggest glassy alloy is $\mathrm{Pd}_{42.5} \mathrm{Cu}_{30} \mathrm{Ni}_{7.5} \mathrm{P}_{20}$ with a diameter of $80 \mathrm{~mm}$ and a length $85 \mathrm{~mm}$ prepared by a water-quenching method in $2012^{23}$.

In the development history of metallic glasses, Al-based metallic glasses have occupied special important situation because of the expectation to develop a high specific strength material. In the 1970s, Al-metalloid and Al-TM

*e-mail: changfan2012@126.com (transition metal) binary alloys prepared by splat quenching were reported to have a mixed structure of amorphous and crystalline phases ${ }^{24-28}$. In 1981, Inoue et al. ${ }^{29}$ prepared fully amorphous alloys in Al-(Fe, Co)-B systems by melt spinning for the first time. Subsequently, they reported that an amorphous phase is formed in melt-spun Al-(Fe, Mn)-Si alloy ribbons ${ }^{30,31}$. However, these amorphous alloys in AlTM-metalloid systems were not always ductile and hence no systematic data on fundamental properties were obtained. In 1988, Inoue et al. ${ }^{32-34}$ and He et al. ${ }^{35,36}$ succeeded in synthesizing Al-based amorphous alloys with good ductility in Al-ETM-LTM (ETM=IV-VI group transition metals, and LTM=VII and VIII group transition metals) and Al-RE-LTM ( $\mathrm{RE}=$ lanthanide group metal) systems as well as in Al-RE binary system. The Al-RE-LTM glassy alloys are the most popular at present because of their higher strength, higher glass-forming ability (GFA), and the appearances of glass transition and supercooled liquid region. Al-based metallic glasses, which can be regarded as an important group of metallic glasses, have a wide range of applications ${ }^{37}$. Their high specific strength combined with outstanding corrosion resistance allows us to expect their application to medical fields ${ }^{38}$. In addition, their good ductility as well as excellent corrosion resistance behavior ${ }^{39-42}$ makes them a promising candidate in engineering applications to structural and coating materials ${ }^{43}$. Al-based metallic glasses can also exhibit a degradation property as an organic water contaminant when highly reactive elements such as $\mathrm{Ca}$ or $\mathrm{Mg}$ are included ${ }^{44}$. 
However, the GFA of Al-based metallic glasses is relatively low comparing with other metallic glasses, resulting in the limitation of applications. Such relatively low GFA has been attributed to the following two aspects: (1) their formation ranges are located in Al-rich composition range which is largely away from their eutectic point ${ }^{45}$; (2) the bonding mode of Al-RE, Al-ETM and Al-LTM pairs is covalent-like so as to enable easy precipitation of Al-based compounds. Thus, the most significant issue is how to enhance the GFA of Al-based metallic glasses ${ }^{46,47}$. Over the past few decades, the researchers devoted themselves to look for an approach for designing and predicting the best glass-forming composition in Al-RE-LTM base systems ${ }^{46,48-53}$. Although no general rules are applicable to predict the GFA, one has noticed various criterions and parameters ${ }^{54-60}$ which are useful and meaningful for the study on the properties of Al-based metallic glasses.

It is well known that the outstanding properties of glassy alloys result from the structure of atomic packing. Therefore, the atomic-level understanding of the structural characteristics is important for developing a new BMG with high GFA. Since the synthesis of Al-based metallic glasses with good mechanical properties in $1988^{32-36}$, much effort has been devoted to clarify the structural features in conjunction with the structure origin for the appearance of glass transition. The previous structural models and empirical criteria for characterizing ordinary metallic glasses do not always fit for Al-based metallic glasses ${ }^{61}$. For example, most of BMGs with good GFA are usually located at and/or near a eutectic composition region, but Al-RE-TM glassy alloys are formed at the compositions which are away from their eutectic points ${ }^{62}$. The compositional feature of Al-based metallic glasses fit the atomic size criteria employed for producing BMGs, but their compositions deviate significantly to the Al-rich side ${ }^{63,64}$. Besides, the minor addition improving the GFA has little effect on majority of Al-based metallic glasses ${ }^{43}$ and not all Al-based metallic glasses have a clear glass transition phenomenon ${ }^{65,66}$. Hence, understanding the structure and mechanism for glass formation in metallic glasses is not an easy work. The objective of this paper is to provide a review of Al-based metallic glasses in the aspects of the local structure, thermal stability and crystallization behavior. The accurate knowledge can promote the understanding on the effect of local atomic configuration structure on fundamental properties and contribute to future development and applications of Al-based metallic glasses.

\section{Structural features of Al-based metallic glasses}

Except for the experimental approaches, computer simulations have played an equal and sometimes more significant role in the understanding of experimental data and the prospection of properties. They are also useful in understanding the dominant factors for glass formation and can be applied for investigating an isolated effect of certain factors that are otherwise difficult to study experimentally ${ }^{67}$. Theoretical calculation is another important method. For example, Liao et al. used the theoretical calculation method to explore the $\mathrm{GFA}^{68}$, since the size limitation makes difficult to investigate the critical cooling rate of Al-based metallic glasses. So far, the local structure of Al-based metallic glasses has not been completely uncovered, but several structural models have been provided for describing the structure features. These structural models not only can provide a theory foundation and instruction for further studying the structural characteristics, but also assist to look for a new Al-based metallic glass with better properties.

\subsection{Structure and GFA of Al-ETM-LTM ternary metallic glasses}

Al-ETM-LTM alloys such as Al-Zr-Ni and Al-V-Cu ${ }^{69}$ glasses are one group of Al-based metallic glasses. In AlETM-LTM system, $\mathrm{Zr}$ and $\mathrm{Hf}$ are the most effective elements to form the amorphous phase, followed by $\mathrm{Ti}, \mathrm{V}, \mathrm{Mo}, \mathrm{Nb}$, $\mathrm{Cr}$ and then $\mathrm{Ta}^{70}$.

Al-Zr-LTM glassy alloys have been widely reported ${ }^{71-74}$, in which Al-Zr-Ni alloy is the most popular due to its high GFA. The glassy Al-Zr-Ni alloys can be made in a rather wide composition range from 10 to 30 at $\% \mathrm{Ni}$ and 5 to 20 at $\% \mathrm{Zr}^{33}$. In $\mathrm{Al}-\mathrm{Zr}-\mathrm{Ni}$ system, Yang et al. ${ }^{75}$ have recognized the multiple maximum peaks in GFA in a single eutectic system, in which $\mathrm{Al}_{75.5} \mathrm{Zr}_{5.5} \mathrm{Ni}_{19}$ and $\mathrm{Al}_{82} \mathrm{Zr}_{5} \mathrm{Ni}_{13}$ alloys are maximum in glass formation. This demonstrates that more than one best glass former can be found in a single eutectic system and the glass formation could result from an intricate balance of kinetic, thermodynamic and topological factors. The Al-ETM-LTM glassy alloys usually show a narrow supercooled liquid region and relatively low thermal stability, limiting their usage as engineering materials. Adding rare earth elements in Al-LTM amorphous alloys can improve the thermal stability ${ }^{76}$. However, the addition of Pr into Al-Zr$\mathrm{Ni}$ alloys can promote the GFA while declines the thermal stability ${ }^{77}$, suggesting the unsuitability of the coexistent $\mathrm{Zr}$ and RE elements because of their positive heats of mixing.

By means of (X-ray diffraction) XRD, Audebert et al. ${ }^{78}$ investigated the structure of Al-Nb-Fe glassy alloys. They illuminated that the glass formation of $\mathrm{Al}-\mathrm{Nb}-\mathrm{Fe}$ alloys results from the strong interatomic interaction between $\mathrm{A} 1$ and $\mathrm{Fe}$. During cooling process, such a strong interaction between A1 and Fe not only decreases the interatomic distances of the Al-TM and Al-Al pairs, but also avoids TM atoms becoming neighbors, leading to the highly stable amorphous alloys. Later, the experiments by Audebert et al. ${ }^{79}$ show that the Al-Nb-Fe alloys have higher GFA than the Al-Nb-Ni alloys. It does not agree with the thermodynamic data ${ }^{80}$ that the Al-Ni interaction is stronger than the Al-Fe interaction. The formation of icosahedral clusters in the liquid is easy for the Al-Nb-Fe alloys. However, the local structure in 
$\mathrm{Al}-\mathrm{Nb}-\mathrm{Ni}$ liquid is similar to that in $\mathrm{Al}_{3} \mathrm{Ni}$ phase which is formed during rapid solidification. Thus, the GFA cannot be determined only by the strong atomic interaction, indicating that the topology of the clusters formed in the liquid also plays a significant role in the GFA.

\subsection{Structure and GFA of Al-RE binary metallic glasses}

Amorphous Al-RE binary alloys ${ }^{32,81}$ with much higher specific strength have been formed in the ranges of 9 to $13 \% \mathrm{Y}, 7$ to $11 \% \mathrm{La}$ or Ce, 10 at $\% \mathrm{Pr}, 8$ to $12 \% \mathrm{Nd}$ or Gd, 8 to $16 \% \mathrm{Sm}, 9$ to $14 \% \mathrm{~Tb}$, and $9-12 \% \mathrm{Dy}, \mathrm{Ho}, \mathrm{Er}$, or $\mathrm{Yb}$. Inoue et $\mathrm{al}^{82}$ found that the as-quenched phase is an face-centered cubic (fcc) supersaturated solid solution in the RE content ranges below the glass formation ranges, amorphous + unidentified phases in the higher RE content ranges exceeding slightly the glass formation ranges, and stable fcc- $\mathrm{Al}+\mathrm{Al}_{11} \mathrm{RE}_{3}$ (or $\mathrm{Al}_{3} \mathrm{RE}$ ) in the $\mathrm{RE}$ content ranges much higher than the glass-forming ranges.

The RE element plays a significant role in the formation of Al-RE amorphous alloys. The attractive bonding nature was thought to be the largest for Al-RE pairs ${ }^{83}$. The glass formation in Al-RE alloys by liquid quenching is mainly likely to a strong attractive interaction of the constituent elements as well as the volume mismatch by the difference in the atomic size ratio ${ }^{84}$. Enhancing the attractive interaction could lead to a much sluggish atomic rearrangement in supercooled liquid. Consequently, the nucleation and growth reactions are restrained, leading to high GFA.

The Al-Sm system has been mainly chosen for the study on the structure and GFA, because it has the widest glass formation range in Al-RE binary alloy series. Kalay et al. ${ }^{85,86}$ studied the structures of as-quenched amorphous and liquid Al-Sm alloys by using the atom probe tomography (APT) and high-resolution transmission electron microscopy (HRTEM). In the cooling process, the quenching rate is high enough to completely bypass fcc-Al nanocrystal precipitation. The amorphous Al-Sm alloys form a skeleton-like structure that is similar to cross-linking in a polymer. The Sm-rich regions form a continuous open network which surrounds the regions of almost pure $\mathrm{Al}$ with a size range of 2-5 $\mathrm{nm}$. Later, Kalay $^{87}$ used the reverse Monte Carlo (RMO) simulations and HEXRD experiments to construct the structural model of amorphous structures. The results show that the Smcentered clusters are always highly coordinated with $16 \mathrm{Al}$ atoms in the first shell, which agrees with the results obtained by X-ray absorption fine structure (XAFS) ${ }^{88}$. The further investigation with Voronoi Tessellation analysis indicates that the first shell neighborhood of Sm atoms in as-quenched state is similar to the high temperature metastable $\mathrm{Al}_{11} \mathrm{Sm}_{3}$ tetragonal phase. The structure of Al-Tb glassy alloys exhibits similar characteristics with the Al-Sm alloys ${ }^{89}$. Kalay also pointed out that the strongly attractive and strong bond between $\mathrm{Al}$ and $\mathrm{Tb}$ atoms lead to a strong compositional fluctuation in the liquid. These regions of Al-Tb clusters act like "superatoms" which can divide the matrix into nanoscale regions enriched with $\mathrm{Al}$, as shown in Figure 1 (a). At relatively high quenching rates, the entire sample will form an amorphous phase because the structure lies below the critical nucleation size. Such amorphous structures are separated into Al-rich and Al-depleted regions as indicated in Figure 1 (b), in which Al-rich regions consist of nearly pure Al, while Al-depleted regions have nearly the Al-75 at.\% $\mathrm{Tb}$ composition. However, some of the Al-rich regions may form the medium-range order (MRO) Al shown in Figure 1 (b) if the quenching rate is not high enough.

Recently, Sun et al. ${ }^{90,91}$ identified the Sm-centered "3661" as the dominant short-range order (SRO) in Al-Sm glassy alloys by using the cluster alignment method. The Sm-centered "3661" consists of a top triangle, two consecutive hexagons and a bottom atom. Its side view and top view are shown in Figure 2 (a) and (b), respectively. Owing to the marginal glass formability in Al-Sm glassy alloys, the "3661" clusters do not form an interconnected interpenetrating network. Most "3661" clusters have only one neighbor, forming a "dimer"- (a)

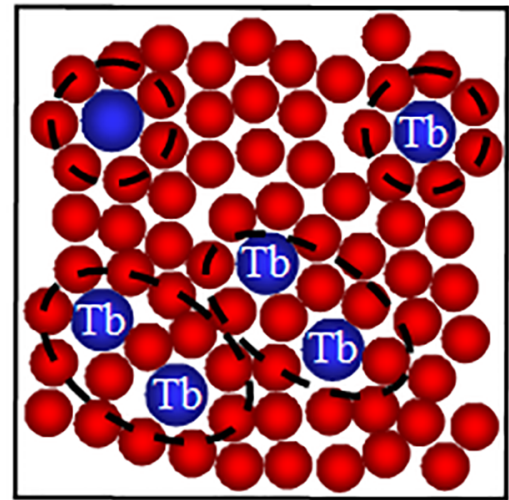

(b)

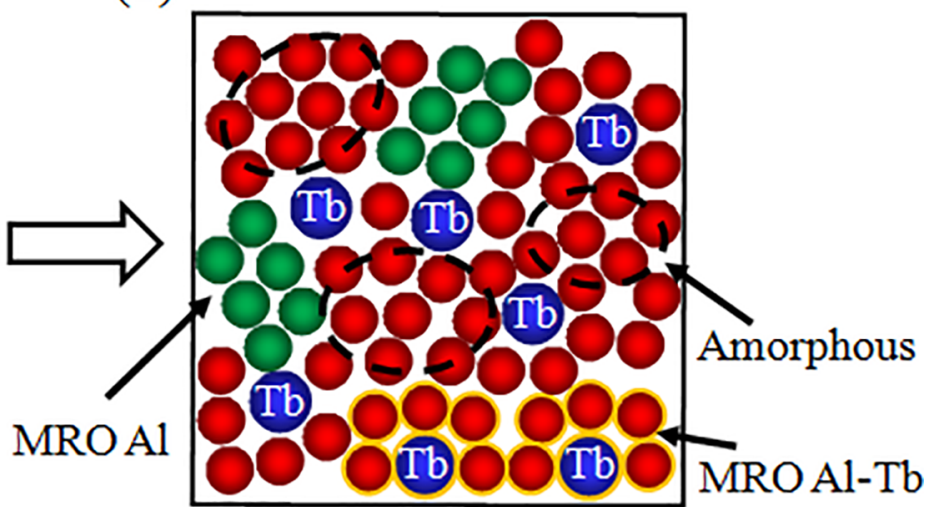

Figure 1. Schematics showing the chemical fluctuation in (a) liquid; (b) as-quenched $\mathrm{Al}_{90} \mathrm{~Tb}_{10}{ }^{89}$ 
(a)

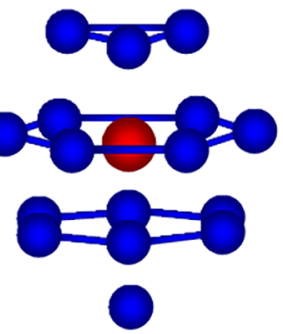

(b)

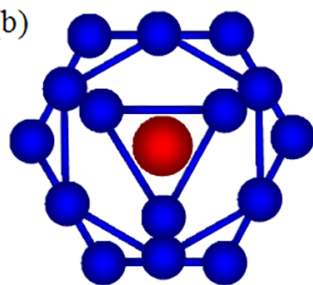

(c)
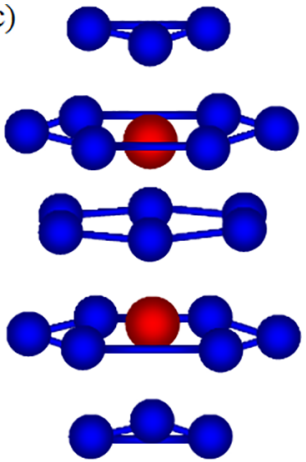

$\mathrm{Sm}$

$\mathrm{Al}$

Figure 2. "3661" short-range order surrounding Sm atoms: (a) the side view; (b) the top view; (c) interpenetration of two "3661" clusters. $^{91}$

like structure. The interpenetration structure illustrated in Figure 2 (c) has the highest possibility in Al-Sm glassy alloys.

\subsection{Structure and GFA of Al-RE-LTM ternary metallic glasses}

In 1988, Inoue et al. ${ }^{34,92}$ found the Al-RE-LTM (LTM = $\mathrm{Fe}, \mathrm{Co}, \mathrm{Ni}$, or $\mathrm{Cu}$ ) ternary metallic glasses by substitution ETM with RE. Compared with Al-ETM-LTM alloys, the Al-RE-LTM alloys have a higher probability of forming bulk metallic glasses. The glass formation is favored in the composition range of $80-92$ at $\% \mathrm{Al}, 3-20$ at $\% \mathrm{RE}$ and $1-15$ at $\% \mathrm{LTM}^{93}$. The glass formation range is the widest for AlRE-Ni system, followed by Al-RE-Co, Al-RE-Fe and then Al-RE-Cu. Therefore, the Al-RE-Ni alloys have attracted much attention as the basic system to search for Al-based BMGs. In 2010, Al-based metallic glasses with a diameter up to $1 \mathrm{~mm}$ were obtained in $\mathrm{Al}-\mathrm{Y}-\mathrm{Ni}-\mathrm{Co}-\mathrm{Sc}$ and $\mathrm{Al}-\mathrm{Y}-$ La-Ni-Co systems on the basic alloy of $\mathrm{Al}_{86} \mathrm{Ni}_{8} \mathrm{Y}_{6}{ }^{94}$, which makes the preparation of high-strength Al-based glassy alloy sheet feasible. This formation is an important breakthrough for Al-based metallic glasses. In 2016, Wu et al. ${ }^{95}$ reported the modified composition $\mathrm{Al}_{86} \mathrm{Ni}_{6.75} \mathrm{Co}_{2.25} \mathrm{Y}_{3.25} \mathrm{La}_{1.75}$ which is regarded as the best glass-forming for Al-based bulk metallic glasses so far. By combining the microalloying effect and the concept of Fermi sphere-Brillouin zone interaction, the alloy could form a glassy phase in the rod of $1.5 \mathrm{~mm}$ in diameter. Recently, the Al-based metallic glass with a diameter of 2.5 $\mathrm{mm}$ was formed at the same alloy composition by salt-fluxing treatment ${ }^{96}$. However, it is still lagging far behind other based metallic glasses. The improvement of GFA also seems to indicate the effectiveness of multiplication alloy components.

Through the experiments such as neutron scattering, $\mathrm{X}$-ray scattering, transmission electron microscopy (TEM) and extended X-Ray absorption fine structure (EXAFS), the local structure of Al-based metallic glasses has been clarified.

The main structural information of Al-based metallic glasses has been presented in references ${ }^{97,98}$. Their structure features can be summarized as below:

1. TM and RE atoms are surrounded by $\mathrm{Al}$ atoms because the composition is very Al-rich ${ }^{88,99}$.

2. The distance between $\mathrm{Al}$ and $\mathrm{TM}$ is shortened than the sum of radii, indicating that a strong interaction of covalent bonding results from electron orbital hybridization between the Al-3p state and TM-3d state ${ }^{64,88,100-106}$. Moreover, in $\mathrm{Al}_{88} \mathrm{Ce}_{8} \mathrm{Co}_{4}$ system, Bin et al. found that the structural inhomogeneity is attributed to the diversity of Al-Co clusters, which leads to loosely and densely packed local atomic configurations and contributes to soft (liquid-like) and hard (solid-like) regions ${ }^{107}$.

3. The distance between $\mathrm{Al}$ and RE atoms is close to the sum of radii of atoms $\mathrm{s}^{64,99,108}$. In addition, the RE atoms are basically randomly distributed ${ }^{109}$.

4. The local RE environment is in a more disordered state as compared with the TM environment ${ }^{100,104,105}$.

5. There exist the icosaherdral-like ordered configurations in Al-based metallic glasses ${ }^{110-114}$.

\subsubsection{Is the structure of Al-based metallic glasses truly amorphous?}

At the early stage, the conventional X-ray diffraction (XRD) technique was usually used to study the structure of metallic glasses. The typical characteristic of XRD patterns for metallic glasses is a broad diffuse diffraction peak. However, whether a material exhibiting a broad diffuse X-ray diffraction has a truly amorphous structure or consists of randomly oriented microcrystals ${ }^{115}$ has ever been an intensive debate. Later, in 1990, He et al. ${ }^{116}$ studied the structure of $\mathrm{Al}_{90} \mathrm{Fe}_{5} \mathrm{~Gb}_{5}$ by means of high-resolution electron microscopy (HREM). They did not observe any crystalline structure in the HREM image and the differential scanning calorimetry (DSC) also verified an amorphous nature of $\mathrm{Al}_{90} \mathrm{Fe}_{5} \mathrm{~Gb}_{5}{ }^{117}$.

\subsubsection{Backbone structure}

It has been indicated that alloy composition, atomic size and component mixing state have an important effect on the GFA ${ }^{118-121}$. During long-term research, Inoue's group ${ }^{122}$ discovered three empirical rules for the stabilization of supercooled liquid, i.e., (1) the alloy contains at least three elements, (2) the atomic size mismatch is over about $12 \%$, and (3) the enthalpies of mixing among the main three constituent elements are negative. It is also known that the multicomponent glassy alloys with the three component rules can have a MRO atomic configuration with highly packed state. Al-based alloys also satisfy this principle such as AlNiY and AlNiTiZr systems ${ }^{123,124}$. According to the atom size-composition relationships, Poon et al. ${ }^{125}$ correlated the GFA with alloy composition and grouped the BMGs into two types. One is MSL (majority atom-small atom-large 
atom), referring to the system with mid-size atoms $(60-70$ at.\%), small-size atoms and large-size atoms ( 10 at.\%). The other is LS (large atom-small atom) system composed with large-size atoms ( 40-75 at.\%) and small-size atoms ( $\sim 25-60$ at.\%). Figure 3 shows a sketch of atomic network formed by large atoms and small atoms in the MSL class metallic glasses, in which the red balls are large atoms and the blue balls are small atoms. The large atoms and small atoms are connected to form a strong L-S network or reinforced "backbone" structures. Such structures can enhance the stability of supercooled liquid and further suppress crystallization. The optimal content of $\mathrm{L}$ atoms for forming BMGs is about 10 at.\%. Much L atoms will tend to form the cluster, which reduces the interaction between the $\mathrm{L}$ atoms and the $\mathrm{M}$ and $\mathrm{S}$ atoms ${ }^{126}$. For the Al-RE-TM ternary metallic glasses, the RE is large-size atoms and $\mathrm{TM}$ is the small-size atoms. By studying the maximum thickness and mixing enthalpy between two constituents for $\mathrm{Al}_{85} \mathrm{Ni}_{10} \mathrm{Ce}_{5}, \mathrm{Al}_{89} \mathrm{Co}_{6} \mathrm{Ce}_{5}, \mathrm{Al}_{90} \mathrm{Fe}_{5} \mathrm{Ce}_{5}$ and $\mathrm{Al}_{84} \mathrm{Cu}_{9} \mathrm{Ce}_{7}$, the results show that the mixing enthalpy of RE-TM is not consistent with the critical thickness ${ }^{58}$. This indicates that

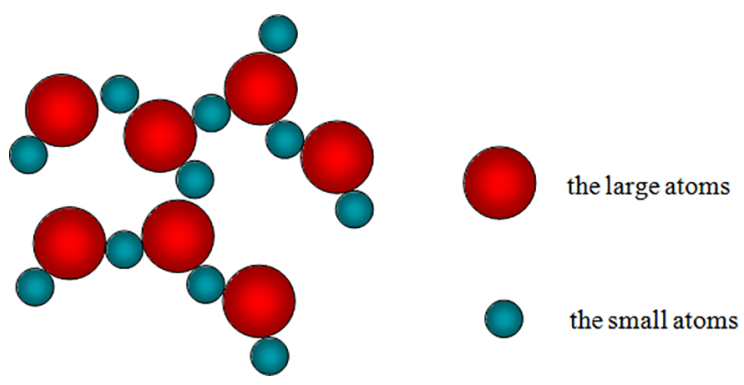

Figure 3. Backbone structure model. ${ }^{125}$

(a)

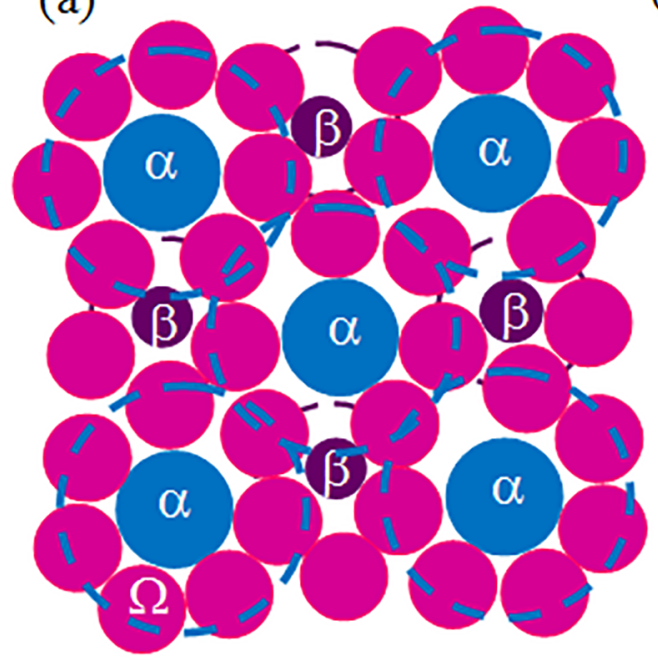

not all glass formability of Al-RE-TM can be explained by the formation of RE-TM pairs.

\subsubsection{Efficient cluster packing (ECP) model}

In 2003, Miracle and Scenkov ${ }^{127}$ specifically proposed a model for Al-based metallic glasses in which the solute centered cluster can predict the SRO. In this model, the solute centered cluster is formed with solvent atom Al at the vertexes of the cluster due to the strong interaction of unlike atoms ${ }^{63}$. However, the model does not display the structure of MRO. Therefore, the efficient cluster packing (ECP) model was provided by Miracle ${ }^{128,129}$ to account for the MRO. The ECP model obeys the basic packing principle and the atoms are regarded as hard spheres. According to the special solute/solvent atomic radius ratio, one can evaluate the expected coordination number $(\mathrm{CN})$ of the solute atom, and then alloying elements can be chosen to form the high GFA compositions ${ }^{107}$. Figure 4 (a) displays the ECP model, where $\alpha$ is solute atom surrounded by 12 solvent atoms $\Omega$, such packing structure can result in octahedral and tetrahedral sites. A secondary solute atom $\beta$ occupies the tetrahedral sites and tertiary solutes $\gamma$ occupy octahedral sites, which make the atom packing more effective. In this atomic packing, there exist SRO within a single solute-centered cluster, and MRO at distances of 1-1.5 $\mathrm{nm}^{88}$. The ECP model has provided a new insight into the designing of the potential BMG forming Albased alloys from the topological perspective. For example, the composition $\mathrm{Al}_{75} \mathrm{~V}_{12.5} \mathrm{Fe}_{12.5}$ was obtained by the ECP model ${ }^{130}$. The ECP model can well predict the composition of RE ( $\alpha$ atoms), but the concentrations of TM $(\beta)$ and Al $(\Omega)$ cannot be predicted very accurately. Later, Wang et al. ${ }^{131}$

(b)

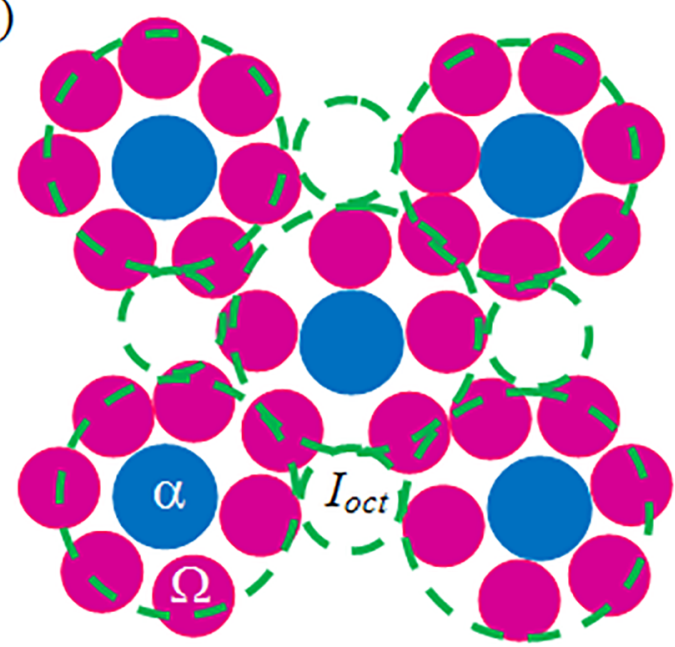

Figure 4. (a) ECP model ${ }^{129}$; (b) modified ECP model $^{131}$. In the figure, $\alpha$ is the primary cluster-forming solute, $\beta$ is the secondary solute, $\Omega$ is the solvent atom, $I_{o c t}$ is octahedral interstitial site. 
proposed the modified ECP. As shown in Figure 4 (b), in which the pink spheres are $\Omega$ solvent atoms and the blue spheres are $\alpha$ solute atoms, the cluster-octahedral interstitial sites $\left(I_{o c t}\right)$ can be filled with single or double $\beta$ solute atoms. The modified ECP model can reduce the deviation by $2-3 \%$ in the prediction of composition ${ }^{132}$.

\subsubsection{Short-to-medium-range order model}

Sheng et al. ${ }^{133,134}$ proposed the quasi-equivalent clusters to characterize Al-based amorphous alloys. They considered several types of polyhedra as quasi-equivalent clusters on the basis of their similar sizes and CN. The atoms of the clusters are treated as rigid balls. For Al-based metallic glasses, the solute TM and RE are surrounded by the solvent Al only, forming an icosahedral-like structure. These RE-centered clusters and TM-centered clusters are interconnected by sharing solvent atoms to form the medium-range order. Figure 5 shows the structure of $\mathrm{Al}_{89} \mathrm{La}_{6} \mathrm{Ni}_{5}$ glass, in which $\mathrm{Ni}$-centered clusters are as a group of quasi-equivalent cluster, and La-centered clusters are as another group of quasiequivalent clusters. These clusters overlap and interconnect via face-sharing, edge-sharing and vertex-sharing to form the Al-based metallic glass.

Based on the features of RE- and TM-centered clusters, Ma et al. ${ }^{135}$ proposed a cluster line method to design Al-based metallic glasses. The optimum glass-forming composition can be considered as the intersection point by drawing the two clusters lines in the ternary phase diagram. Hence their intersection is assumed to indicate the best BMG-forming compositions which can be confirmed experimentally ${ }^{136,137}$. Figure 6 displays the structure model they used. They regarded the distance between the solvent and solute atoms

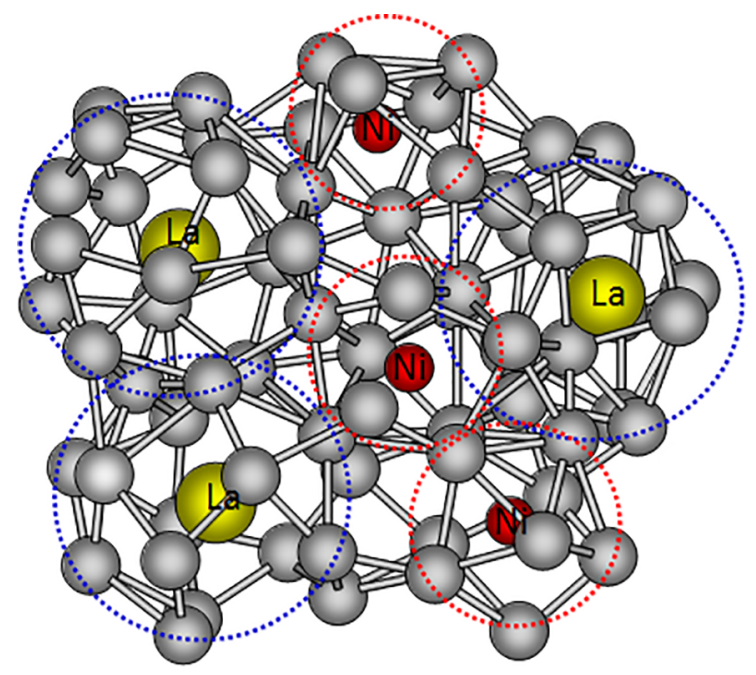

Figure 5. Quasi-equivalent clusters in Al-based metallic glasses ${ }^{134}$. $\mathrm{La}$
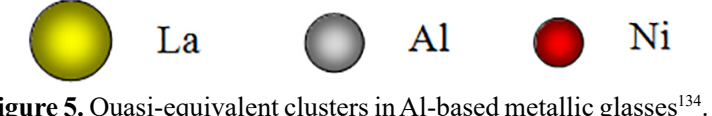

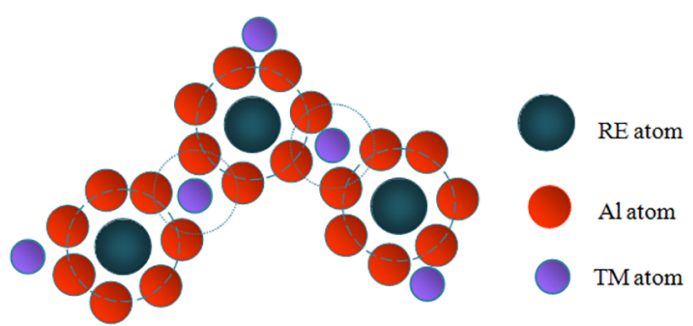

Figure 6. A skeleton of cluster packing in Al-based MGs. ${ }^{135}$

as the sum of their nominal atomic radii with fixed sizes, and the RE- and TM-centered clusters are connected through $\mathrm{Al}$ atoms. The well-known compositions ${ }^{94}$ firstly formed into a fully glassy rod of $1 \mathrm{~mm}$ were obtained by using the cluster line method. However, the experiment ${ }^{138}$ of Liu et al. did not support the cluster line method with regard to predicting the composition with optimum GFA. In view of the interaction between different elements, Zhang et al. ${ }^{139}$ proposed the modified cluster line method by considering the effective atomic radii. The proposed method can predict the optimum glass-forming composition of Al-Ni-RE systems more accurately.

\subsubsection{Icosahedral supercluster MRO structure model}

More recently, combined with the efficient atomic packing and electrochemical potential equalization principle, Wu et al. ${ }^{140}$ proposed the efficient atomic packing-chemistry coupled model (EAPCC) for calculating and predicting the best glass-forming compositions in Al-RE-TM metallic glasses. The composition of Al-RE-TM alloys can be represented as $\left(A l_{N}-R E\right) T M_{X}$, where $N$ is the coordination number in the first shell, and $\mathrm{x}$ is the number of TM atoms which is determined by the equalization of electrochemical potential between RE- and TM-centered clusters. The RE-centered clusters are packed as spherical periodic order (SPO) that is regarded as the basic frame of microstructure. The SPO results from the global resonance between the electronic and atomic subsystem. The TM atoms are located at the interstitial sites between RE-centered clusters, and such packing style makes the structure more efficient.

Based on the EAPCC, Wu et al. ${ }^{141}$ further proposed an icosahedral supercluster MRO structure model to describe the connection between the clusters. A supercluster consists of 12 RE-centered clusters or 12 TM-centered clusters on the vertex of the supercluster, in which the centered TM and $\mathrm{RE}$ are surrounded only by $\mathrm{Al}$ atoms. In the center of the supercluster, there exist RE-centered clusters or TM-centered clusters. Such atomic packing will produce 20 tetrahedral interstices filled with TM or RE atoms. Figures 7 (a) and (b) display the $2 \mathrm{D}$ schematics for the cluster-tetrahedral 

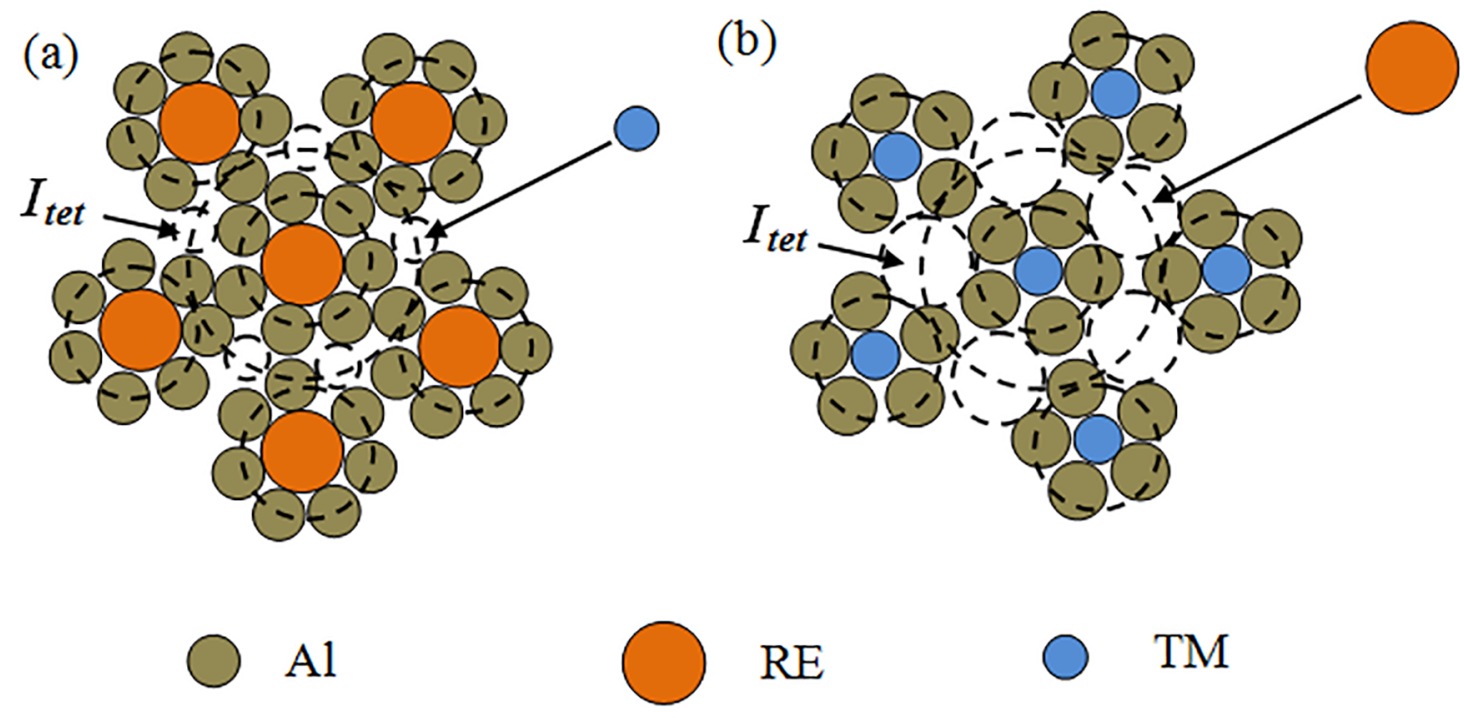

$\mathrm{RE}$

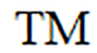

Figure 7. Icosahedral supercluster MRO structure model: (a) TM atoms occupy the tetrahedral sites; (b) RE atoms occupy the tetrahedral sites. ${ }^{141}$

sites occupied by TM and RE, respectively. The model was verified well by the Al-Ni-La system.

\section{Crystallization of Al-based metallic glasses}

\subsection{The modes of crystallization}

Crystallization of Al-based metallic glasses is such a process during which an amorphous phase transforms into one or more metastable or stable crystalline phases ${ }^{142}$. In most cases, crystallization in Al-based metallic glasses is induced by thermal treatment containing isothermal and continuous heating mode ${ }^{143-145}$. However, it may also occur when it is subject to corrosion-induced crystallization ${ }^{146}$, irradiation-induced crystallization ${ }^{147}$, and deformationinduced crystallization, including bending ${ }^{148,149}$, high-press torsion straining ${ }^{150,151}$, ball milling ${ }^{152,153}$, and cold rolling ${ }^{154,155}$.

Crystallization reaction in the metallic glasses is highly dependent on the alloy composition ${ }^{156-158}$. It is usually divided into three types, labelled as polymorphous, eutectic and primary crystallization, as illustrated for the crystallization of the amorphous Fe-B alloys as an example ${ }^{159}$. Figure 8(a) presents the polymorphous crystallization where a single crystalline phase is formed and its composition is the same as the amorphous matrix. No long-range diffusion is required in this process. Figure 8 (b) presents the eutectic crystallization. The glass matrix transforms simultaneously into two (or more) crystalline phases. In this process, no long-range diffusion is required. Figure $8(\mathrm{c})$ presents the primary crystallization mode in which a crystal with different composition from that of the matrix is embedded in an amorphous matrix.
For the Al-based metallic glasses, these modes of crystallization have also been reported. For example, the melt-spun $\mathrm{Al}_{75} \mathrm{Cu}_{15} \mathrm{~V}_{10}$ metallic glass was transformed into a single icosahedral phase by annealing, demonstrating a polymorphous crystallization ${ }^{160}$. The $\mathrm{Al}_{85} \mathrm{Y}_{11} \mathrm{Ni}_{4}$ metallic glass is subjected to the eutectic crystallization during annealing and transforms into the fcc- $\mathrm{Al}, \mathrm{Al}_{3} \mathrm{Y}$ and some unidentified metastable intermetallic phases ${ }^{161}$. Similarly, $\mathrm{Al}_{89} \mathrm{La}_{6} \mathrm{Ni}_{5}$ metallic glass crystallizes into fcc-Al and a metastable bcc-(AlNi) ${ }_{11} \mathrm{La}_{3}$-like phase ${ }^{162}$, indicating a eutectic type crystallization. Compared with the polymorphous or eutectic crystallization, primary crystallization is an overall slow phenomenon ${ }^{163}$. It is the main mode of transformation in Al-based metallic glasses. Primary crystallization occurs in Al-rich compositions, in which a high density of $\mathrm{Al}$ nanocrystals with diameters ranging from 7 to $20 \mathrm{~nm}$ dispersed in the amorphous matrix ${ }^{164}$. The mechanical properties of such amorphous/nanocrystal composites are strongly related to the volume fraction $\left(\mathrm{V}_{\mathrm{f}}\right)$ of fcc-Al nanocrystals ${ }^{165}$. By controlling the $\mathrm{V}_{\mathrm{f}}$ of fcc-Al nanocrystals, the higher strength can be obtained than that of the corresponding amorphous alloy ${ }^{166}$. Usually, the nanoscale mixed structure consisting of fcc-Al embedded in an amorphous matrix can be obtained by the thermal treatment in an amorphous phase. The $\mathrm{V}_{\mathrm{f}}$ of the fcc-Al phase is correlated with annealing time ${ }^{86,167,168}$ and can be calculated using the DSC program ${ }^{169}$, XRD method $^{170}$, or transmission electron microscopic (TEM) images $^{171}$. Comparing with the TEM method, the DSC and XRD methods are preferable, because these two methods can reflect the entire characteristics of the sample ${ }^{165}$. One can also obtain such structure directly during melt-spinning, when the cooling rate is controlled. The $V_{f}$ of the fcc-Al 

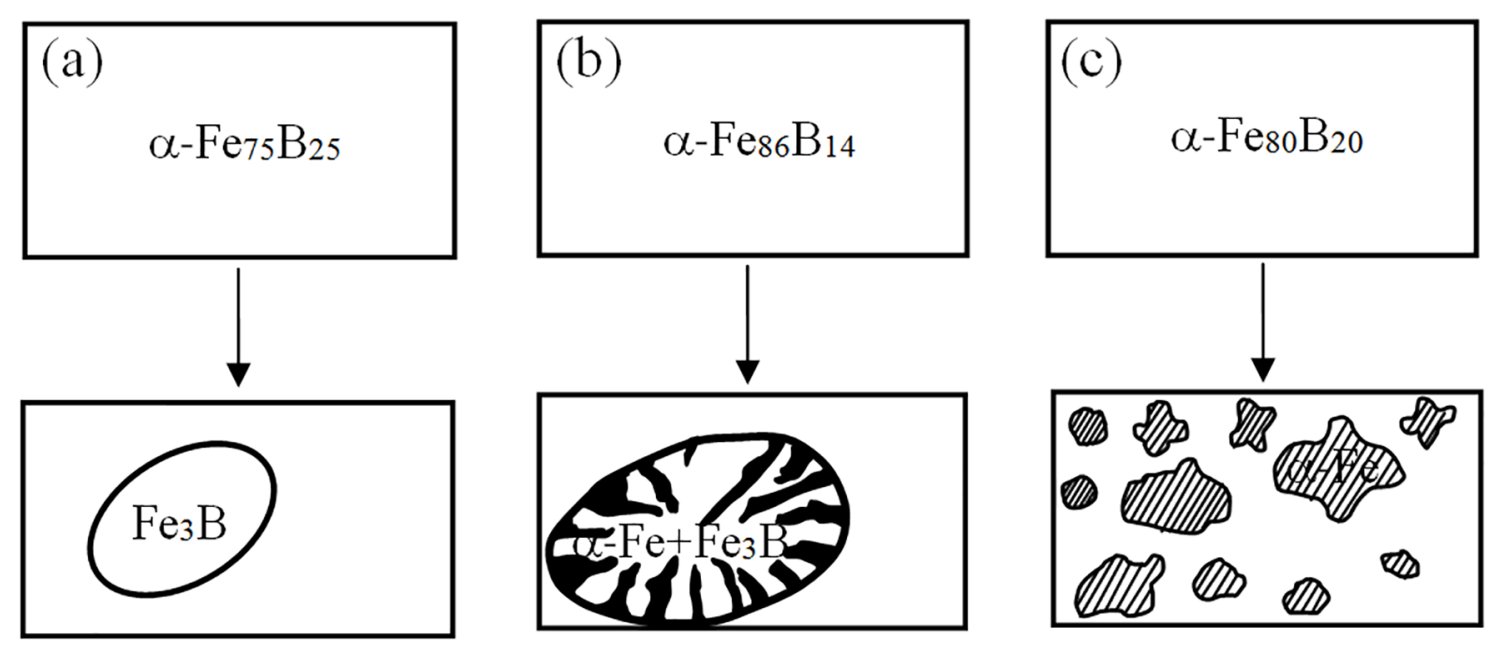

Figure 8. The schematic of the crystallization ${ }^{159}$ : (a) polymorphous crystallization; (b) eutectic crystallization; (c) primary crystallization.

phase is controlled by changing the rotation speed of wheel or the ejecting temperature of molten alloy ${ }^{172,173}$. Compared with the controlling of cooling rate during melt-spinning, annealing an amorphous phase with suitable composition is a more controllable method to produce an optimum volume fraction of the fcc-Al ${ }^{174}$.

Minor element as an addition to Al-based metallic glasses plays an important role in crystallization behavior. Here, several examples about minor element doping in the $\mathrm{Al}$-based systems are given. Doping $\mathrm{Pb}$ into the $\mathrm{Al}-\mathrm{Y}-\mathrm{Fe}$ alloy, the crystallization onset temperature ( $T_{x}$ ) decreases by $20^{\circ} \mathrm{C}$. As the extrinsic spatial heterogeneity, the insoluble $\mathrm{Pb}$ nanoparticles in the amorphous matrix can provide the nucleation sites for Al-fcc precipitation ${ }^{175}$. As a result, crystalline phase is more easily formed from the amorphous phase by heterogeneous nucleation ${ }^{176}$. Doping the $\mathrm{Pb}$ into the Al-Ni-Ce alloy is very effective in enhancing the thermal stability of metallic glasses, and the $T_{x}$ is greatly improved ${ }^{177}$. Such phenomenon is also observed when adding the Ca into Al-Y-Ni-Co system ${ }^{178}$. A tiny change in the alloy composition may also lead to a dramatic change in the crystallization process. Doping the Si into the Al-Ni-Nd system results in a transformation of a primary crystallization from eutectic crystallization, while the addition of Co makes a primary crystallization transform into a eutectic crystallization ${ }^{179}$. Crystallizing the amorphous Al-Fe-Ce by annealing at $613 \mathrm{~K}$ for $2 \mathrm{~h}$, the structure of fcc- $\mathrm{Al}+$ icosahedral phase + amorphous phase can be obtained and fcc-Al is a majority phase. However, icosahedral phase is dominant when adding $\mathrm{Ti}$ in the Al-Fe-Ce system ${ }^{180}$.

It is worth noting that several novel phenomena were found in Al-based metallic glasses in the last two years. In 2017, the structure consisting of amorphous and fcc-Al phase was observed for the first time by the reverse crystallization when treating the continuous heating on $\mathrm{Al}_{84} \mathrm{Y}_{9} \mathrm{Ni}_{4} \mathrm{Co}_{1.5} \mathrm{Fe}_{0.5} \mathrm{Pd}_{1}$ metallic glass ${ }^{145}$. In this process, the eutectic reaction takes place firstly, then the metastable multicomponent compound phase disappears and the volume fraction of amorphous phase increases. This reverse crystallization makes the amorphous + fcc-Al phases to be formed in a wide range of high temperature, which provides a good chance for developing Al-based alloys with high elevated-temperature strength. In 2018, the fcc-Al phase was found by polymorphous crystallization when the amorphous $\mathrm{Al}_{90} \mathrm{Y}_{10}$ and $\mathrm{Al}_{84} \mathrm{Y}_{8.5} \mathrm{Ni}_{4} \mathrm{Co}_{2} \mathrm{Pd}_{1} \mathrm{Fe}_{0.5}$ were subjected to the cold-rolling ${ }^{155}$. Compared with the primary crystallization of fcc-Al embedded in an amorphous matrix, such amorphous/nanocrystal structure obtained by polymorphous crystallization could lead to the softening. It is clearly contrary to the annealing-induced crystallization that usually leads to the hardening. The discovery of this important phenomenon is beneficial to the development of Al-based metallic glasses as structural materials.

\subsection{Mechanism of nanocrystallization for Al- based metallic glasses.}

At present, studying the primary crystallization mode for Al-based metallic glasses is the main objective. Understanding the primary crystallization and structural evolutions not only contributes to the development of the novel amorphous/ nanocrystal products, but also plays an important part to uncover the glass formation and develop fabrication processes $^{181,182}$. In the primary crystallization, Al-based metallic glasses crystallize to an amorphous/nanocrystal composite, in which a high density of Al nanocrystals are embedded in an amorphous matrix. This process needs high nucleation frequency and low growth velocity ${ }^{183}$. The classical nucleation theory is difficult to explain such high nucleation density. In light of this, several models are proposed, including "quenched in nuclei", "coupled-flux model", and "phase separation in amorphous state".

During the fast cooling rate, some clusters with MRO are quenched in the amorphous alloys. These clusters are considered 
as the "quenched-in nuclei". They are too small at higher temperatures but become overcritical at lower temperatures. When annealing, the quenched-in nuclei provide a high density of heterogeneous nucleation sites and the subsequent growth results in the rapid crystallization ${ }^{184,185}$. Therefore, nanocrystallization results from an extremely high density of quenched-in nuclei. Quenched in nuclei is one possible mechanism for explaining the high density of nanocrystals. In view of the linked stochastic fluxes of interfacial attachment and diffusion in the cluster neighborhood, Russel1 ${ }^{186}$ proposed a simplified model to explain nucleation. In this model, three important regions including the cluster, the neighborhood around the cluster, and the parent phase, are defined, as shown in Figure 9. The cluster population distribution correlates with not only the cluster size, but also the solute atomic number in the nearest neighbor shell around the cluster; Cluster growth is influenced by the relative exchange rates of atoms in the parent phase and the cluster. ${ }^{187,188}$ Based on this, Kelton ${ }^{189}$ proposed a new homogeneous nucleation model (coupled-flux model) that couples the interfacial and long-range diffusion fluxes. Upon cooling, the clusters are quenched and their distribution is more representative of the steady-state distribution at high temperature. The size of the clusters is smaller than the critical size, and the composition of the shell neighborhood is closer to the crystal composition. At the annealing temperature, the clusters larger than the critical size will grow, in which the growth is initially interface limited, resulting in a rapid increase of small nuclei. ${ }^{190}$ The coupled-flux model has successful explained the formation of the nanocrystal in $\mathrm{Al}_{88} \mathrm{Y}_{7} \mathrm{Fe}_{5}$ without phase separation during the low temperature annealing treatment.

Phase separation (also denoted as chemical decomposition) is a common phenomenon in the study of the Al-based metallic glasses. For a single amorphous phase, there always exhibit a broad diffraction peak in the XRD and diffuse halo rings in the bright-field image for TEM. In the study of the $\mathrm{Al}-\mathrm{Si}$ (or $\mathrm{Ge})-\mathrm{X}(\mathrm{X}=\mathrm{Cr}, \mathrm{Mn}, \mathrm{Fe}, \mathrm{Co}, \mathrm{Ni})$ metallic glasses, the split X-ray and electron haloes were first observed, demonstrating that the system is not a single amorphous phase but separates into two amorphous phases. ${ }^{191,192} \mathrm{Except}$ for the "quenched in nuclei" and "coupled-flux model", another possible nanocrystallization mechanism is the result of nanoscale phase separation which may occur prior to

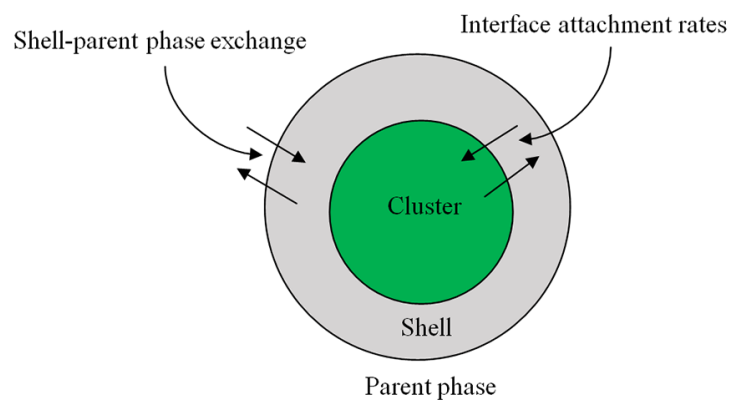

Figure 9. Schematic of the coupled-flux model. ${ }^{189}$ nanocrystallization ${ }^{193}$. For example, it was observed that the TEM image of $\mathrm{Al}_{88} \mathrm{La}_{2} \mathrm{Gd}_{6} \mathrm{Ni}_{4}$ presents the bright regions and darker regions ${ }^{194}$, indicating that a phase separates into the two phases. These two regions are proved to be the Al-rich and solute-rich amorphous regions, respectively. The first nucleation of the fcc-Al nanocrystal starts preferentially near the boundaries of phase-separated regions. In the $\mathrm{Al}_{92} \mathrm{Sm}_{8}$ and $\mathrm{Al}_{91} \mathrm{Gd}_{9}$ metallic glasses, the nanoscrystals were observed to be formed inside the Al-rich regions ${ }^{195}$. Phase separation phenomenon prior to nanocrystallization is a mechanism triggering nanocrystallization ${ }^{183,194,196}$. The pure $\mathrm{Al}$ zone seems to catalyze the fcc-Al nucleation, which is responsible for the high nucleation frequency. The solute rich regions between the Al-rich regions inhibit the long-range diffusion, resulting in the low growth rates ${ }^{184}$. There are also some reports in several alloy systems that no phase separation phenomenon was observed, illustrating its strong dependence on alloy composition and system ${ }^{144}$. However, controversial results were reported even in the same materials by different analytical techniques. For example, the phase separation in $\mathrm{Al}_{88} \mathrm{Gd}_{6} \mathrm{Er}_{2} \mathrm{Ni}_{4}$ is resulted from the TEM preparation conditions ${ }^{197}$. Therefore, it is still an open issue about the occurrence of phase separation in Al-based metallic glasses ${ }^{198}$.

\section{Conclusions}

This paper mainly introduces the features of the structure characteristics and crystallization of Al-based metallic glasses. The main conclusions of this review are summarized as follows:

1. Understanding the structure in combination with alloy compositions contributes to making the size of Al-based metallic glasses larger, which is important for applications. The structure models could give an intuitive image of structure and provide a foundation for investigating characteristic and performance of new glassy alloys. One can construct the structure model at atomic level based on the features of local atomic arrangements. After several decades of unremitting efforts, the structure models of Albased metallic glasses have been developed, and further efforts to develop new models are expected to enable the interpretation on the electronic effect on the GFA and characteristics of Al-based metallic glasses. However, the cognition of electronic structure and its influence on Al-based metallic glasses has not perfectly been obtained, and more future detailed research is required.

2. The primary crystallization is strongly dependent on the solute constituent in the Al-based metallic glasses and its crystallization product consists of an ultrahigh density of fcc-Al embedded in amorphous matrix for Al-based alloys with high 
Al contents above 85 at $\%$ and $\mathrm{Al}+$ compound for Al-based alloys with Al contents less than 85 at $\%$. The former amorphous/nanocrystal composites have higher strength than the amorphous single phase state. At present, the advances have been obvious on the understanding of primary crystallization, but there are still several problems needed to be further solved, such as (1) the mechanism for the precipitation of very high density of fcc-Al; (2) the compositional feature and origin for phase separation; (3) micro-alloying and cold deformation effects on the pathway of crystallization. In addition, the advanced experimental and simulation techniques for analysis of local structure also need to be developed urgently, which contribute to the future development of Al-based metallic glasses as structural materials. We also need to be pay attention to the effect of multicomponent on the thermodynamic and kinetic aspects of GFA, thermal stability and crystallization, because the crystallization mode involving nucleation and growth significantly changes with solute composition. Thus, the clarification on the compositional dependence of structure, thermal stability and crystallization of metallic glasses is an important way for understanding the fundamental characteristics of Al-based glassy alloy.

\section{Acknowledgments}

This work was supported by the NSFC (Grant No. 50971057 and 51371099). CTL is thankful for the financial support provided by the Research Grant Council (RGC), the Hong Kong Government through the General Research Fund (GRF) with the account number of City U 102013.

\section{References}

1. Klement Jun W, Willens RH, Duwez P. Non-crystalline structure in solidified gold-silicon alloys. Nature. 1960;187(4740):869870 .

2. Inoue A, Shen BL, Koshiba H, Kato H, Yavari AR. Ultra-high strength above $5000 \mathrm{MPa}$ and soft magnetic properties of CoFe-Ta-B bulk glassy alloys. Acta Materialia. 2004;52(6):16311637.

3. Yavari AR, Lewandowski JJ, Eckert J. Mechanical Properties of Bulk Metallic Glasses. MRS Bulletin. 2007;32(8):635-638.

4. Su C, Chen Y, Yu P, Song M, Chen W, Guo SF. Linking the thermal characteristics and mechanical properties of $\mathrm{Fe}$-based bulk metallic glasses. Journal of Alloys and Compounds. 2016;663:867-871.

5. Greer AL. Metallic glasses. Science. 1995;267(5206):19471953.

6. Pang SJ, Zhang T, Asami K, Inoue A. Synthesis of Fe-Cr-MoC-B-P bulk metallic glasses with high corrosion resistance. Acta Materialia. 2002;50(3):489-497.
7. Wang WH, Dong C, Shek CH. Bulk metallic glasses. Materials Science and Engineering: R: Reports. 2004;44(2-3):45-89.

8. Guan BR, Shi XT, Dan ZH, Xie GQ, Niinomi M, Qin FX. Corrosion behavior, mechanical properties and cell cytotoxity of Zr-based bulk metallic glasses. Intermetallics. 2016;72:69-75.

9. Inoue A. Bulk Glassy Alloys: Historical Development and Current Research. Engineering. 2015;1(2):185-191.

10. Schroers J. Processing of Bulk Metallic Glass. Advanced Materials. 2010;22(14):1566-1597.

11. Inoue A, Nakamura T, Nishiyama $\mathrm{N}$, Masumoto T. Mg-Cu-Y Bulk Amorphous Alloys with High Tensile Strength Produced by a High-Pressure Die Casting Method. Materials Transactions, JIM. 1992;33(10):937-945.

12. Borowski A, Guwer A, Gawlas-Mucha A, Babilas R, Nowosielski R. Fabrication of Mg-based bulk metallic glasses by pressure die casting method. Indian Journal of Engineering \& Materials Sciences. 2014;21(3):259-264.

13. Liu CT, Heatherly L, Horton JA, Easton DS, Carmichael CA, Wright JL, et al. Test environments and mechanical properties of Zr-base bulk amorphous alloys. Metallurgical and Materials Transactions A. 1998;29(7):1811-1820.

14. Jing Q, Liu RP, Shao GJ, Wang WK. Preparation and super-plastic deformation of the $\mathrm{Zr}$-based bulk metallic glass. Materials Science and Engineering: A. 2003;359(1-2):402-404.

15. Wu X, Xue CE. Size Effect on the Micro-Extrusion Forming of Zr-Based Amorphous Alloys. Advanced Materials Research. 2011;228-229:586-591.

16. Wang X, Shao Y, Gong P, Yao KF. Effect of thermal cycling on the mechanical properties of $\mathrm{Zr}_{41} \mathrm{Ti}_{14} \mathrm{Cu}_{12.5} \mathrm{Ni}_{10} \mathrm{Be}_{22.5}$ alloy. Science China Physics, Mechanics and Astronomy. 2012;55(12):2357-2361.

17. Kim YC, Kim WT, Kim DH. A development of Ti-based bulk metallic glass. Materials Science and Engineering: A. 2004;375377:127-135.

18. Men H, Pang SJ, Inoue A, Zhang T. New Ti-Based Bulk Metallic Glasses with Significant Plasticity. Materials Transactions. 2005;46(10):2218-2220.

19. Liu DM, Zhu ZW, Li ZK, Zhang L, Fu HM, Wang A, et al. Modulating work-hardening behaviors and tensile plasticity of in-situ formed ductile dendrite Ti-based bulk metallic glass composites with tailored dendrite composition. Scripta Materialia. 2018;146:22-26.

20. Inoue A, Zhang T, Takeuchi A. Bulk amorphous alloys with high mechanical strength and good soft magnetic properties in Fe-TM-B (TM= IV-VIII group transition metal) system. Applied Physics Letters. 1997;71(4):464-466.

21. Pawlik P, Davies HA, Gibbs MRJ. Magnetic properties and glass formability of $\mathrm{Fe}_{61} \mathrm{Co}_{10} \mathrm{Zr}_{5} \mathrm{~W}_{4} \mathrm{~B}_{20}$ bulk metallic glassy alloy. Applied Physics Letters. 2003;83(14):2775-2777.

22. Pan MX, Wang WH, Hu Y, Zhao DQ, Zhao YH, Okada T, et al. Stability and Formation Ability of Fe-Based Bulk Metallic Glasses under High Pressure. Journal of Metastable and Nanocrystalline Materials. 2004;20-21:53-58.

23. Nishiyama N, Takenaka K, Miura H, Saidoh N, Zeng YQ, Inoue A. The world's biggest glassy alloy ever made. Intermetallics. 2012;30:19-24. 
24. Predecki P, Giessen BC, Grant NJ. New Metastable Alloy Phases of Gold Silver and Aluminum. Transactions of the Metallurgical Society of AIME. 1965;233(7):1438.

25. Davies HA, Hull JB. An amorphous phase in a splat-quenched A1-17.3 at\% Cu alloy. Scripta Metallurgica. 1972;6(3):241-245.

26. Ramachandrarao P, Laridjani M, Cahn RW. Diamond as a SplatCooling Substrate. Zeitschrift für Metallkunde. 1972;63(1):43-49.

27. Furrer P, Warlimont H. Crystalline and amorphous structures of rapidly solidified Al-Cr alloys. Materials Science and Engineering. 1977;28(1):127-137.

28. Scott MG, Kijek M, Matyja H, Williams DB, Edington JW. Some comments on the microstructure of rapidly quenched Al-Cu alloys. Journal of Materials Science. 1978;13(6):1354-1357.

29. Inoue A, Kitamura A, Masumoto T. The effect of aluminium on mechanical properties and thermal stability of $(\mathrm{Fe}, \mathrm{Co}, \mathrm{Ni})$ Al-B ternary amorphous alloys. Journal of Materials Science. 1981;16(7):1895-1908.

30. Suzuki RO, Komatsu Y, Kobayashi KF, Shingu PH. Formation and crystallization of Al-Fe-Si amorphous alloys. Journal of Materials Science. 1983;18(4):1195-1201.

31. Inoue A, Bizen Y, Masumoto T. Quasicrystalline phase in Al-Si-Mn system prepared by annealing of amorphous phase. Metallurgical Transactions A. 1988;19(2):383-385.

32. Inoue A, Ohtera K, Masumoto T. New Amorphous Al-Y, Al-La and Al-Ce Alloys Prepared by Melt Spinning. Japanese Journal of Applied Physics. 1988;27(5A):L736.

33. Tsai AP, Inoue A, Masumoto T. Formation of metal-metal type aluminum-based amorphous alloys. Metallurgical Transactions A. 1988;19(5):1369-1371.

34. Inoue A, Ohtera K, Kita K, Masumoto T. New Amorphous Alloys with Good Ductility in Al-Ce-M ( $\mathrm{M}=\mathrm{Nb}, \mathrm{Fe}, \mathrm{Co}, \mathrm{Ni}$ or $\mathrm{Cu}$ ) Systems. Japanese Journal of Applied Physics. 1988;27(Pt 2 10):L1796.

35. He Y, Poon SJ, Shiflet GJ. Synthesis and Properties of Metallic Glasses that Contain Aluminum. Science. 1988;241(4873):16401642 .

36. He Y, Poon SJ, Shiflet GJ. Formation and stability of aluminumbased metallic glasses in Al-Fe-Gd alloys. Scripta Metallurgica. 1988;22(11):1813-1816.

37. Henao J, Concustell A, Cano IG, Dosta S, Cinca N, Guilemany JM, et al. Novel Al-based metallic glass coatings by Cold Gas Spray. Materials \& Design. 2016;94:253-261.

38. Löffler JF. Recent progress in the area of bulk metallic glasses. Zeitschrift für Metallkunde. 2006;97(3):225-233.

39. Wang YG, Li YJ, Pan SP, Fu BD, Qin JY, Wang WM. Role of Yttrium Substitution in the Atomic Cluster Evolution and Corrosion Behaviour of Al-Ni-Gd Metallic Glasses. International Journal of Electrochemical Science. 2016;11:3512-3531.

40. He Y, Dougherty GM, Shiflet GJ, Poon SJ. Unique metallic glass formability and ultra-high tensile strength in Al-Ni-Fe-Gd alloys. Acta Metallurgica et Materialia. 1993;41(2):337-343.

41. Freitag JM, Koknaev RG, Sabet-Sharghi R, Koknaeva M, Altounian Z. Mechanical properties of Al-Y-Ni amorphous ribbons. Journal of Applied Physics. 1996;79(8):3967-3970.
42. Tsai AP, Kamiyama T, Kawamura Y, InoueA, Masumoto T. Formation and precipitation mechanism of nanoscale Al particles in Al-Ni base amorphous alloys. Acta Materialia. 1997;45(4):1477-1487.

43. Shi XM, Wang XD, Yu Q, Cao QP, Zhang DX, Zhang J, et al. Structure alterations in Al-Y-based metallic glasses with $\mathrm{La}$ and $\mathrm{Ni}$ addition. Journal of Applied Physics. 2016;119(11):114904.

44. Wang PP, Wang JQ, Li H, Yang H, Huo JT, Wang JG, et al. Fast decolorization of azo dyes in both alkaline and acidic solutions by Al-based metallic glasses. Journal of Alloys and Compounds. 2017;701:759-767.

45. Wang JQ, Dong P, Hou WL, Chang XC, Quan MX. Synthesis of Al-rich bulk metallic glass composites by warm extrusion of gas atomized powders. Journal of Alloys and Compounds. 2013;554:419425 .

46. Mu J, Fu H, Zhu Z, Wang A, Li H, Hu Z, et al. Synthesis and properties of Al-Ni-La bulk metallic glass. Advanced Engineering Materials. 2009;11(7):530-532.

47. Yi JJ, Xiong XZ, Inoue A, Kong LT, Li JF. Glass forming ability of Al-Ni-La alloys with Si addition. Journal of Alloys and Compounds. 2015;650:578-583.

48. Jun JH, Kim JM, Kim KT, Jung WJ. Glass formability and thermal stability of Al-Ni-Y-Be amorphous alloys. Journal of Alloys and Compounds. 2007;434-435:190-193.

49. Huang Z, Li J, Rao Q, Zhou Y. Thermal stability and primary phase of Al-Ni(Cu)-La amorphous alloys. Journal of Alloys and Compounds. 2008;463(1-2):328-332.

50. Song KK, Bian XF, Lv XQ, Guo J, Li GH, Xie MT. Compositional dependence of glass-forming ability, medium-range order, thermal stability and liquid fragility of Al-Ni-Ce-based amorphous alloys. Materials Science and Engineering: A. 2009;506(1-2):87-93.

51. Huang ZH, Li JF, Rao QL, Zhou YH. Crystallization behaviors of Al-Ni-La amorphous alloys with trace Ti and B. Journal of NonCrystalline Solids. 2009;355(2):154-158.

52. Yan M, Kohara S, Wang JQ, Nogita K, Schaffer GB, Qian M. The influence of topological structure on bulk glass formation in Al-based metallic glasses. Scripta Materialia. 2011;65(9):755-758.

53. Zhang Z, Xiong XZ, Yi JJ, Li JF. Effects of substitution of La by other rare-earth elements on the glass forming ability of $\mathrm{Al}_{86} \mathrm{Ni}_{9} \mathrm{La}_{5}$ alloy. Journal of Non-Crystalline Solids. 2013;369:1-4.

54. Guo FQ, Poon SJ, Shiflet GJ. Glass Formability in Al-based Multinary Alloys. Materials Science Forum. 2000;331-337:31-42.

55. Lisboa RS, Bolfarini C, Botta Filho WJ, Kiminami C. Topological instability as a criterion for design and selection of aluminum-based glass-former alloys. Applied Physics Letters. 2005;86(21):211904.

56. Bian XF, Sun BA, Hu LN, Jia YB. Fragility of superheated melts and glass-forming ability in Al-based alloys. Physics Letters A. 2005;335(1):61-67.

57. Ma CS, Zhang J, Chang XC, Hou WL, Wang JQ. Electronegativity difference as a factor for evaluating the thermal stability of Al-rich metallic glasses. Philosophical Magazine Letters. 2008;88(12):917924.

58. Yang H, Wang JQ, Li Y. Influence of TM and RE elements on glass formation of the ternary Al-TM-RE systems. Journal of Non-Crystalline Solids. 2008;354(29):3473-3479. 
59. Yang BJ, Yao JH, Zhang J, Yang HW, Wang JQ, Ma E. Al-rich bulk metallic glasses with plasticity and ultrahigh specific strength. Scripta Materialia. 2009;61(4):423-426.

60. Zhuo LC, Pang SJ, Wang H, Zhang T. Ductile Bulk AluminumBased Alloy With Good Glass-Forming Ability And High Strength. Chinese Physics Letters. 2009;26(6):066402.

61. Yi F. Medium range order in Al-based metallic glasses. [Ph.D. Dissertation]. Madison: University of Wisconsin-Madison; 2011.

62. Guo FQ, Enouf SJ, Poon SJ, Shiflet GJ. Formation of ductile A1based metallic glasses without rare-earth elements. Philosophical Magazine Letters. 2001;81(3):203-211.

63. Sun BA, Pan MX, Zhao DQ, Wang WH, Xi XK, Sandor MT, et al. Aluminum-rich bulk metallic glasses. Scripta Materialia. 2008;59(10):1159-1162.

64. Saksl K, Jóvári P, Franz $\mathrm{H}$, Jiang JZ. Atomic structure of $\mathrm{Al}_{88} \mathrm{Y}_{7} \mathrm{Fe}_{5}$ metallic glass. Journal of Applied Physics. 2005;97(11):113507.

65. Sahoo KL, Sahu R. Glass transition and crystallization of AlNi-La based metallic glasses studied by temperature modulated DSC. Journal of Non-Crystalline Solids. 2013;365:33-36.

66. Demirtas T, Kalay YE. Kinetics of fcc-Al nanocrystallization in $\mathrm{Al}_{90} \mathrm{~Tb}_{10}$ metallic glass. Journal of Non-Crystalline Solids. 2013;378:71-78

67. Miller ML, Liaw P, eds. Bulk Metallic Glasses: An Overview. New York: Springer US; 2008.

68. Liao JP, Yang BJ, Zhang Y, Lu WY, Gu XJ, Wang JQ. Evaluation of glass formation and critical casting diameter in Al-based metallic glasses. Materials \& Design. 2015;88:222-226.

69. Tsai AP, Inoue A, Masumoto T. Ductile Al-Cu-V amorphous alloys without metalloid. Metallurgical Transactions A. 1988;19(2):391393.

70. Inoue A, Ohtera K, Masumoto T. Recent progress of aluminum base amorphous alloys. Science Reports of the Research Institutes, Tohoku University, Series A: Physics, Chemistry and Metallurgy. 1990;35(1):115-164.

71. Tsai AP, Inoue A, Masumoto T. Ductile Al-Ni-Zr amorphous alloys with high mechanical strength. Journal of Materials Science Letters. 1988;7(8):805-807.

72. Wang L, Ma L, Kimura H, Inoue A. Amorphous forming ability and mechanical properties of rapidly solidified Al-Zr-LTM (LTM=Fe, $\mathrm{Co}, \mathrm{Ni}$ and $\mathrm{Cu}$ ) alloys. Materials Letters. 2002;52(1-2):47-52.

73. Bai X, Li JH, Li N, Luo SY, Liu BX. Prediction of Glass-Forming Ability and Atomic-Level Structure of the Al-Zr-Pd Metallic Glasses by Molecular Dynamics Simulations. Journal of the Physical Society of Japan. 2013;82(12):124006.

74. Zhou CY, Guo CP, Li CR, Du ZM. Thermodynamic assessment of the phase equilibria and prediction of glass-forming ability of the Al-Cu-Zr system. Journal of Non-Crystalline Solids. 2017;461:47-60.

75. Yang H, Lim KY, Li Y. Multiple maxima in glass-forming ability in Al-Zr-Ni system. Journal of Alloys and Compounds. 2010;489(1):183-187.

76. Wei X, Wang XF, Han FS, Xie HW, Wen CE. Thermal stability of the Al70Ni10Ti10Zr5Ta5 amorphous alloy powder fabricated by mechanical alloying. Journal of Alloys and Compounds. 2010;496(1-2):313-316.
77. Zhang CZ, Bian XF, Guo J, Wang SH, Song KK, Wang CD, et al. Effect of Pr addition on glass-forming ability of Al-Ni-Zr metallic glass alloy. Journal of Alloys and Compounds. 2007;436(1-2):9598.

78. Audebert F, Sirkin H, Garcia Escorial A. Approach to the atomic structure of amorphous Al-Fe-Nb. Philosophical Magazine B. 1997;76(4):483-487.

79. Audebert F, Mendive C, Vidal A. Structure and mechanical behaviour of Al-Fe-X and Al-Ni-X rapidly solidified alloys. Materials Science and Engineering: A. 2004;375-377:1196-1200.

80. Manh DN, Mayou D, Pasturel A, Cyrot-Lackmann F. Electronic structure and hybridisation effects in transition-metal-polyvalentmetal alloys. Journal of Physics F: Metal Physics. 1985;15(9):1911.

81. Akashev LA, Sidorov VE. The optical properties of Al-8 at.\% Ce alloy in the liquid, amorphous, and crystalline states. High Temperature. 2009;47(3):331-335.

82. Inoue A, Ohtera K, Tao Z, Masumoto T. New Amorphous Al$\mathrm{Ln}(\mathrm{Ln}=\mathrm{Pr}, \mathrm{Nd}, \mathrm{Sm}$ or Gd) Alloys Prepared by Melt Spinning. Japanese Journal of Applied Physics. 1988;27(9 Pt 2):L1583.

83. Inoue A, Masumoto T. Light-metal base amorphous alloys containing lanthanide metal. Journal of Alloys and Compounds. 1994;207-208:340-348.

84. Inoue A. Amorphous, nanoquasicrystalline and nanocrystalline alloys in Al-based systems. Progress in Materials Science. 1998;43(5):365-520

85. Kalay YE, Chumbley LS, Anderson IE. Crystallization behavior in a highly driven marginal glass forming alloy. Journal of NonCrystalline Solids. 2008;354(26):3040-3048.

86. Kalay YE, Yeager C, Chumbley LS, Kramer MJ, Anderson IE. Initial crystallization in a nanostructured Al-Sm rare earth alloy. Journal of Non-Crystalline Solids. 2010;356(28-30):1416-1424.

87. Kalay YE, Chumbley LS, Kramer MJ, Anderson IE. Local structure in marginal glass forming Al-Sm alloy. Intermetallics. 2010;18(8):1676-1682.

88. Zalewski W, Antonowicz J, Bacewicz R, Latuch J. Local atomic order in Al-based metallic glasses studied using XAFS method. Journal of Alloys and Compounds. 2009;468(1-2):40-46.

89. Kalay YE, Kalay I, Hwang J, Voyles PM, Kramer MJ. Local chemical and topological order in Al-Tb and its role in controlling nanocrystal formation. Acta Materialia. 2012;60(3):994-1003.

90. Sun Y, Zhang F, Ye Z, Zhang Y, Fang XW, Ding ZJ, et al. 'Crystal Genes'in Metallic Liquids and Glasses. Scientific Reports. 2016;6:23734.

91. Sun Y, Zhang Y, Zhang F, Ye Z, Ding Z, Wang CZ, et al. Cooling rate dependence of structural order in $\mathrm{Al}_{90} \mathrm{Sm}_{10}$ metallic glass. Journal of Applied Physics. 2016;120(1):015901.

92. Inoue A, Ohtera K, Tsai AP, Masumoto T. New Amorphous Alloys with Good Ductility in Al-YM and Al-La-M (M=Fe, $\mathrm{Co}, \mathrm{Ni}$ or $\mathrm{Cu}$ ) Systems. Japanese Journal of Applied Physics. 1988;27(3 Pt 2):L280.

93. Perepezko JH. Nucleation-controlled reactions and metastable structures. Progress in Materials Science. 2004;49(3-4):263-284.

94. Yang BJ, Yao JH, Chao YS, Wang JQ, Ma E. Developing aluminum-based bulk metallic glasses. Philosophical Magazine. 2010;90(23):3215-3231. 
95. Wu NC, Zuo L, Wang JQ, Ma E. Designing aluminum-rich bulk metallic glasses via electronic-structure-guided microalloying. Acta Materialia. 2016;108:143-151.

96. Yang BJ, Lu WY, Zhang JL, Wang JQ, Ma E. Melt fluxing to elevate the forming ability of Al-based bulk metallic glasses. Scientific Reports. 2017;7:11053.

97. Cheng YQ, Ma E. Atomic-level structure and structure-property relationship in metallic glasses. Progress in Materials Science. 2011;56(4):379-473.

98. Wilson TW. Processing, Structure, and Properties of Amorphous Aluminum Alloys. [PhD Dissertation]. Knoxville: University of Tennessee; 2008.

99. Matsubara E, Waseda Y, Inoue A, Ohtera K, Masumoto T. Anomalous $\mathrm{X}$-ray Scattering on Amorphous $\mathrm{Al}_{87} \mathrm{Y}_{8} \mathrm{Ni}_{5}$ and $\mathrm{Al}_{90} \mathrm{Y}_{10}$ Alloys. Zeitschrift für Naturforschung A. 1989;44(9):814-820.

100. Hsieh HY, Toby BH, Egami T, He Y, Poon SJ, Shiflet GJ. Atomic structure of amorphous A190Fex Ce10-x. Journal of Materials Research. 1990;5(12):2807-2812.

101. Mansour A, Wong CP, Brizzolara R. Atomic structure of amorphous $\mathrm{Al}_{100-2 \mathrm{x}} \mathrm{Co}_{\mathrm{x}} \mathrm{Ce}_{\mathrm{x}}(\mathrm{x}=8,9$, and 10$)$ and $\mathrm{Al}_{80} \mathrm{Fe}_{10} \mathrm{Ce}_{10}$ alloys: An XAFS study. Physical Review B. 1994;50(17):12401.

102. Egami T. The atomic structure of aluminum based metallic glasses and universal criterion for glass formation. Journal of Non-Crystalline Solids. 1996;205-207:575-582.

103. Ahn K, Louca D, Poon SJ, Shiflet GJ. Local structure of Al-and Fe-based metallic glasses. Journal of Physics: Condensed Matter. 2003;15(31):S2357.

104. Ahn K, Louca D, Poon SJ, Shiflet GJ. Topological and chemical ordering induced by $\mathrm{Ni}$ and $\mathrm{Nd}$ in $\mathrm{Al}_{87} \mathrm{Ni}_{7} \mathrm{Nd}_{6}$ metallic glass. Physical Review B. 2004;70(22):224103.

105. Saksl K, Jóvári P, Franz H, Zeng QS, Liu JF, Jiang JZ. Atomic structure of $\mathrm{Al}_{89} \mathrm{La}_{6} \mathrm{Ni}_{5}$ metallic glass. Journal of Physics: Condensed Matter. 2006;18(32):7579.

106. Li G, Borisenko KB, Chen Y, Nguyen-Manh D, Ma E, Cockayne DJH. Local structure variations in $\mathrm{Al}_{89} \mathrm{La}_{6} \mathrm{Ni}_{5}$ metallic glass. Acta Materialia. 2009;57(3):804-811.

107. Gu B, Liu F. Characterization of structural inhomogeneity in A188Ce8Co4 metallic glass. Acta Materialia. 2016;112:94-104.

108. Bacewicz R, Antonowicz J. XAFS study of amorphous Al-RE alloys. Scripta Materialia. 2006;54(6):1187-1191.

109. Hsieh HY, Egami T, He Y, Poon SJ, Shiflet GJ. Short range ordering in amorphous $\mathrm{Al}_{90} \mathrm{Fe}_{\mathrm{x}} \mathrm{Ce}_{10-\mathrm{x}}$. Journal of Non-Crystalline Solids. 1991; 135(2-3):248-254.

110. Zhang L, Wu YS, Bian XF, Li H, Wang WM, Li JG, et al. Origin of the prepeak in the structure factors of liquid and amorphous Al-Fe-Ce alloys. Journal of Physics: Condensed Matter. 1999;11(41):7959.

111. Zhang L, Wu Y, Bian X, Li H, Wang W, Wu S. Short-range and medium-range order in liquid and amorphous $\mathrm{Al}_{90} \mathrm{Fe}_{5} \mathrm{Ce}_{5}$ alloys. Journal of Non-Crystalline Solids. 2000;262(1-3):169-176.

112.Zhang C, Wu Y, Cai X, Zhou G, Shi Y, Yang H, et al. Precipitation of an icosahedral phase in amorphous A190Fe5Ce5 alloy. Journal of Physics: Condensed Matter. 2001;13(27):L647.

113.Zhang CJ, Wu YS, Cai XL, Zhao F, Zheng SQ, Zhou GR, et al. Icosahedral phase in rapidly solidified Al-Fe-Ce alloy. Materials Science and Engineering: A. 2002;323(1-2):226-231.
114.Liu CY, Wang F, Rao FF, Hou YS, Wang SY, Sun Q, et al. Glass-forming ability of Al-Co alloy under rapid annealing. Journal of Applied Physics. 2013;113(15):154306.

115. Chen LS, Spaepen F. Calorimetric evidence for the microquasicrystalline structure of 'amorphous' $\mathrm{Al} /$ transition metal alloys. Nature. 1988;336(6197):366-368.

116.He Y, Chen H, Shiflet GJ, Poon SJ. On the structural nature of aluminium-based metallic glasses. Philosophical Magazine Letters. 1990;61(5):297-303.

117.He Y, Shiflet GJ, Poon SJ. Synthesis and properties of aluminumbased metallic glasses containing rare earths. Journal of Alloys and Compounds. 1994;207-208:349-354.

118.Inoue A, Zhang T, Takeuchi A. Ferrous and Nonferrous Bulk Amorphous Alloys. Materials Science Forum. 1998;269272:855-864.

119. Senkov ON, Miracle DB. Effect of the atomic size distribution on glass forming ability of amorphous metallic alloys. Materials Research Bulletin. 2001;36(12):2183-2198.

120.Lu ZP, Liu CT. Role of minor alloying additions in formation of bulk metallic glasses: A Review. Journal of Materials Science. 2004;39(12):3965-3974.

121.Han HS, Park N, Suh JY, Nam HS, Seok HK, Kim WT, et al Reassessing the atomic size effect on glass forming ability: Effect of atomic size difference on thermodynamics and kinetics. Intermetallics. 2016;69:123-127.

122.Inoue A. Stabilization of metallic supercooled liquid and bulk amorphous alloys. Acta Materialia. 2000;48(1):279-306

123.Guo S, Liu Y. Estimation of critical cooling rates for formation of amorphous alloys from critical sizes. Journal of NonCrystalline Solids. 2012;358(20):2753-2758.

124.Wu Y, Wang XF, Han FS. Preparation of $\mathrm{Al}_{72} \mathrm{Ni}_{8} \mathrm{Ti}_{8} \mathrm{Zr}_{6} \mathrm{Nb}_{3} \mathrm{Y}$ amorphous powders and bulk materials. International Journal of Minerals, Metallurgy, and Materials. 2016;23(10):11871195.

125.Poon SJ, Shiflet GJ, Guo F, Ponnambalam V. Glass formability of ferrous- and aluminum-based structural metallic alloys. Journal of Non-Crystalline Solids. 2003;317(1-2):1-9.

126. Stoica M. Methodology and the model alloys. In: Stoica M. FeBased Bulk Metallic Glasses. Wiesbaden: Matwerk - Springer; 2017. p. 21-33.

127.Miracle DB, Senkov ON. A geometric model for atomic configurations in amorphous Al alloys. Journal of Non-Crystalline Solids. 2003;319(1-2):174-191.

128. Miracle DB. A structural model for metallic glasses. Nature Materials. 2004;3:697-702.

129.Miracle DB. The efficient cluster packing model-An atomic structural model for metallic glasses. Acta Materialia. 2006;54(16):4317-4336.

130.Zhu B, Wang XF, Li XY, Wang D, Qin Y, Han FS. Bulk amorphous $\mathrm{Al}_{75} \mathrm{~V}_{12.5} \mathrm{Fe}_{12.5-\mathrm{x}} \mathrm{Cu}_{\mathrm{x}}$ alloys fabricated by consolidation of mechanically alloyed amorphous powders. Journal of Alloys and Compounds. 2014;586:645-649.

131.Wang AP, Wang JQ, Ma E. Modified efficient cluster packing model for calculating alloy compositions with high glass forming ability. Applied Physics Letters. 2007;90(12):121912. 
132.Wang JQ, Ma CS, Zhang J, Hou WL, Chang XE. Progress in research on glass forming ability of Al-based metallic glasses. Chinese Journal of Materials Research. 2008;22(2):113-119.

133. Sheng HW, Luo WK, Alamgir FM, Bai JM, Ma E. Atomic packing and short-to-medium-range order in metallic glasses. Nature. 2006;439:419-425.

134. Sheng HW, Cheng YQ, Lee PL, Shastri SD, Ma E. Atomic packing in multicomponent aluminum-based metallic glasses. Acta Materialia. 2008;56(20):6264-6272.

135.Ma CS, Zhang J, Hou WL, Chang XC, Wang JQ. Efficient atomic packing clusters and glass formation in ternary Al-based metallic glasses. Philosophical Magazine Letters. 2008;88(8):599-605.

136.Dong C, Qiang JB, Wang YM, Jiang N, Wu J, Thiel P. Cluster-based composition rule for stable ternary quasicrystals in $\mathrm{Al}-(\mathrm{Cu}, \mathrm{Pd}, \mathrm{Ni})-\mathrm{TM}$ systems. Philosophical Magazine. 2006;86(3-5):263-274.

137.Pemberton-Pigott N, Wang Q, Chen WR, Zhang QY, Wu J, $\mathrm{Li} \mathrm{YH}$, et al. A cluster line approach to finding new Fe-B-Y$\mathrm{Nb}-\mathrm{Zr}$ bulk metallic glasses. Journal of University of Science and Technology Beijing, Mineral, Metallurgy, Material. 2007;14(Suppl 1):26-30.

138.Liu Y, Schumacher G, Zizak I, Erko A, Banhart J. Local structure and site substitution in $\mathrm{Al}_{86} \mathrm{Ni}_{6} \mathrm{Co}_{2} \mathrm{Y}_{45} \mathrm{La}_{1.5}$ bulk amorphous alloy. Materials Letters. 2012;70:171-173.

139.Zhang Z, Xiong XZ, Zhou W, Lin X, Inoue A, Li JF. Glass forming ability and crystallization behavior of Al-Ni-RE metallic glasses. Intermetallics. 2013;42:23-31.

140.Wu NC, Kan D, Zuo L, Wang JQ. Efficient atomic packingchemistry coupled model and glass formation in ternary Al-based metallic glasses. Intermetallics. 2013;39:1-4.

141.Wu NC, Yan M, Zuo L, Wang JQ. Correlation between mediumrange order structure and glass-forming ability for Al-based metallic glasses. Journal of Applied Physics. 2014;115(4):043523.

142.Zhang LC. Crystallization behavior and control of amorphous alloys. In: Mastai Y, ed. Advances in Crystallization Processes. Rijeka: InTech; 2012.

143.Louzguine-Luzgin DV, Inoue A. Nano-devitrification of glassy alloys. Journal of Nanoscience and Nanotechnology. 2005;5(7):999-1014.

144.Gao MC, Guo F, Poon SJ, Shiflet GJ. Development of fcc-Al nanocrystals in $\mathrm{Al}-\mathrm{Ni}-\mathrm{Gd}$ metallic glasses during continuous heating DSC scan. Materials Science \& Engineering: A. 2008;485(1):532-543.

145.Han FF, Inoue A, Han Y, Kong FL, Zhu SL, Shalaan E, et al. Novel Heating-Induced Reversion during Crystallization of Al-based Glassy Alloys. Scientific Reports. 2017;7:46113.

146. Wang YG, Liu Y, Li YJ, An B, Cao GH, Jin SF, et al. Crystallization of Al-based Amorphous Alloys in Good Conductivity Solution. Journal of Materials Science \& Technology. 2014;30(12):12621270.

147.Huang Y, Zhou B, Fan H, Wang Y, Wang D, Sun J, et al. Effect of ion irradiation in an $\mathrm{Al}_{90} \mathrm{Fe}_{2} \mathrm{Ce}_{8}$ metallic glass. Materials \& Design (1980-2015). 2014;62:133-136.
148. Csontos AA, Shiflet GJ. Formation and chemistry of nanocrystalline phases formed during deformation in aluminum-rich metallic glasses. Nanostructured Materials. 1997;9(1-8):281-289.

149.Jiang WH, Atzmon M. The effect of compression and tension on shear-band structure and nanocrystallization in amorphous A190Fe5Gd5: a high-resolution transmission electron microscopy study. Acta Materialia. 2003;51(14):4095-4105.

150.Boucharat N, Hebert R, Rösner H, Valiev R, Wilde G. Nanocrystallization of amorphous A188Y7Fe 5 alloy induced by plastic deformation. Scripta Materialia. 2005;53(7):823-828.

151.Henits P, Kovács Z, Schafler E, Varga LK, Lábár JL, Révész Á. Nanocrystallization in $\mathrm{Al}_{85} \mathrm{Ce}_{8} \mathrm{Ni}_{5} \mathrm{Co}_{2}$ amorphous alloy obtained by different strain rate during high pressure torsion. Journal of Alloys and Compounds. 2010;504(Suppl 1):S91-S94.

152.He Y, Shiflet GJ, Poon SJ. Ball milling-induced nanocrystal formation in aluminum-based metallic glasses. Acta Metallurgica et Materialia. 1995;43(1):83-91.

153.Kim JJ, Choi Y, Suresh S, Argon AS. Nanocrystallization During Nanoindentation of a Bulk Amorphous Metal Alloy at Room Temperature. Science. 2002;295(5555):654-657.

154.Hebert RJ, Perepezko JH. Effect of cold-rolling on the crystallization behavior of amorphous $\mathrm{Al}_{88} \mathrm{Y}_{7} \mathrm{Fe}_{5}$ alloy. Materials Science and Engineering: A. 2004;375-377:728-732.

155.Bi HW, Inoue A, Han FF, Han Y, Kong FL, Zhu SL, et al. Novel deformation-induced polymorphic crystallization and softening of Al-based amorphous alloys. Acta Materialia. 2018;147:9099.

156.Kulik T. Nanocrystallization of metallic glasses. Journal of Non-Crystalline Solids. 2001;287(1-3):145-161.

157.Basu J, Ranganathan S. Bulk metallic glasses: A new class of engineering materials. Sadhana. 2003;28(3-4):783-798.

158. Suryanarayana C, Inoue A. Bulk Metallic Glasses. 2nd ed. Boca Raton: CRC Press; 2017.

159.Köster U, Herold U. Crystallization of metallic glasses. In: Güntherodt HJ, Beck H, eds. Glassy Metals I: Ionic Structure, Electronic Transport, and Crystallization. Chapter 10. Berlin Heidelberg: Springer-Verlag; 1981. p. 225-259.

160.Holzer JC, Kelton KF. Kinetics of the amorphous to icosahedral phase transformation in $\mathrm{Al}-\mathrm{Cu}-\mathrm{V}$ alloys. Acta Metallurgica et Materialia. 1991;39(8):1833-1843.

161.Gogebakan M, Warren PJ, Cantor B. Crystallization behaviour of amorphous $\mathrm{Al}_{85} \mathrm{Y}_{11} \mathrm{Ni}_{4}$ alloy. Materials Science and Engineering: A. 1997;226-228:168-172.

162.Zhuang YX, Jiang JZ, Lin ZG, Mezouar M, Crichton W, Inoue A. Evidence of eutectic crystallization and transient nucleation in $\mathrm{Al}_{89} \mathrm{La}_{6} \mathrm{Ni}_{5}$ amorphous alloy. Applied Physics Letters. 2001;79(6):743-745.

163.Lisboa RDS, Kiminami CS. Primary crystallization in amorphous $\mathrm{Al}_{84} \mathrm{Ni}_{8} \mathrm{Co}_{4} \mathrm{Y}_{3} \mathrm{Zr}_{1}$ alloy. Journal of Non-Crystalline Solids. 2002;304(1-3):36-43.

164.Perepezko JH, Hebert RJ, Wu RI, Wilde G. Primary crystallization in amorphous Al-based alloys. Journal of Non-Crystalline Solids. 2003;317(1-2):52-61. 
165. Yang HW, Wen J, Quan MX, Wang JQ. Evaluation of the volume fraction of nanocrystals devitrified in Al-based amorphous alloys. Journal of Non-Crystalline Solids. 2009;355(4-5):235-238.

166. Choi GS, Kim YH, Cho HK, Inoue A, Masumoto T. Ultrahigh tensile strength of amorphous Al-Ni-(Nd,Gd)-Fe alloys containing nanocrystalline Al particles. Scripta Metallurgica et Materialia. 1995;33(8):1301-1306.

167. Hong SJ, Kim HS, Suryanarayana C, Chun BS. Isothermal nanocrystallisation behaviour of melt spun $\mathrm{Al}_{86} \mathrm{Ni}_{9} \mathrm{Mm}_{5}$ (Mmmischmetal) amorphous alloy. Materials Science and Technology. 2003;19(7):966-972.

168. Lin JG, Xu J, Wang WW, Li W. Electrochemical behavior of partially crystallized amorphous $\mathrm{Al}_{86} \mathrm{Ni}_{9} \mathrm{La}_{5}$ alloys. Materials Science and Engineering: B. 2011;176(1):49-52.

169. Kim YH, Inoue A, Masumoto T. Ultrahigh tensile strengths of $\mathrm{Al}_{88} \mathrm{Y}_{2} \mathrm{Ni}_{9} \mathrm{M}_{1}(\mathrm{M}=\mathrm{Mn}$ or $\mathrm{Fe})$ amorphous alloys containing finely dispersed fcc-Al particles. Materials Transactions, JIM. 1990;31(8):747-749.

170. Antonowicz J, Yavari AR, Vaughan G. Nanocrystallization of $\mathrm{Al}_{92} \mathrm{Sm}_{8}$ amorphous alloy studied in situ by real-time $\mathrm{x}$-ray diffraction. Nanotechnology. 2004;15(8):1038.

171. Wesseling P, Ko BC, Lewandowski JJ. Quantitative evaluation of a-Al nano-particles in amorphous $\mathrm{Al}_{87} \mathrm{Ni}_{7} \mathrm{Gd}_{6}$-comparison of XRD, DSC, and TEM. Scripta Materialia. 2003;48(11):1537-1541.

172. Kim YH, Inoue A, Masumoto T. Increase in Mechanical Strength of Al-Y-Ni Amorphous Alloys by Dispersion of Nanoscale fcc-Al Particles. Materials Transactions, JIM. 1991;32(4):331-338.

173. Inoue A, Kimura H. Fabrications and mechanical properties of bulk amorphous, nanocrystalline, nanoquasicrystalline alloys in aluminum-based system. Journal of Light Metals. 2001;1(1):31-41.

174. Kim YH, Hiraga K, Inoue A, Masumoto T. Crystallization and High Mechanical Strength of Al-Based Amorphous Alloys. Materials Transactions, JIM. 1994;35(5):293-302.

175. Shen Y, Perepezko JH. The effect of minor addition of insoluble elements on transformation kinetics in amorphous $\mathrm{Al}$ alloys. Journal of Alloys and Compounds. 2015;643(Suppl 1):S260-S264.

176. Wu YH, Wang C, Hsueh CH, Li TH, Chang CH, Chen HC, et al. Microstructure and mechanical properties of $\mathrm{Zr}-\mathrm{Ti}-\mathrm{Cu}-\mathrm{Nd}$ metallic glass composites. Journal of Alloys and Compounds. 2017;702:318-326.

177. Sha P, Qi Z, Zhang Z. Effect of Ag or Pd additions on the microstructure, crystallization and thermal stability of Al-Ni-Ce amorphous alloys. Intermetallics. 2010;18(9):1699-1706.

178. Wang JQ, Liu YH, Imhoff S, Chen N, Louzguine-Luzgin DV, Takeuchi A, et al. Enhance the thermal stability and glass forming ability of Al-based metallic glass by Ca minor-alloying. Intermetallics. 2012;29:35-40.

179. Wang SH, Bian XF. Effect of Si and Co on the crystallization of Al-Ni-RE amorphous alloys. Journal of Alloys and Compounds. 2008;453(1-2):127-130.

180. Singh D, Singh D, Mandal RK, Srivastava ON, Tiwari RS. Crystallization behavior and mechanical properties of $\left(\mathrm{Al}_{90} \mathrm{Fe}_{5} \mathrm{Ce}_{5}\right)_{100-}$ $\mathrm{Ti}_{x}$ amorphous alloys. Journal of Alloys and Compounds. 2016;687:990-998.
181.Li Q, Johnson E, Madsen MB, Johansen A, Sarholt-Kristensen L. Crystallization of Al-based metallic glasses. Structural aspects. Philosophical Magazine B. 1992;66(4):427-442.

182. Wilde G, Boucharat N, Hebert RJ, Rösner H, Tong WS, Perepezko $\mathrm{JH}$. Nanocrystallization in Al-rich metallic glasses. Advanced Engineering Materials. 2003;5(3):125-130.

183.Antonowicz J, Yavari AR, Botta WJ, Panine P. Phase separation and nanocrystallization in $\mathrm{Al}_{92} \mathrm{Sm}_{8}$ metallic glass. Philosophical Magazine. 2006;86(27):4235-4242.

184.Pekarskaya E, Löffler JF, Johnson WL. Microstructural studies of crystallization of a $\mathrm{Zr}$-based bulk metallic glass. Acta Materialia. 2003;51(14):4045-4057.

185. Shen Y, Perepezko JH. Al-based amorphous alloys: Glass-forming ability, crystallization behavior and effects of minor alloying additions. Journal of Alloys and Compounds. 2017;707:3-11.

186. Russell KC. Linked flux analysis of nucleation in condensed phases. Acta Metallurgica. 1968;16(5):761-769.

187. Kelton KF. Kinetic model for nucleation in partitioning systems Journal of Non-Crystalline Solids. 2000;274(1-3):147-154.

188.Kelton KF. Time-dependent nucleation in partitioning transformations. Acta Materialia. 2000;48(8):1967-1980.

189.Kelton KF. A new model for nucleation in bulk metallic glasses. Philosophical Magazine Letters. 1998;77(6):337-344.

190.Kelton KF. Liquid structure and long range diffusion: Their impact on glass formation and nanoscale devitrification. Intermetallics. 2006;14(8-9):966-971.

191.Inoue A, Yamamoto M, Kimura HM, Masumoto T. Ductile aluminium-base amorphous alloys with two separate phases. Journal of Materials Science Letters. 1987;6(2):194-196.

192.Inoue A, Bizen Y, Kimura HM, Masumoto T, Sakamoto M. Compositional range, thermal stability, hardness and electrical resistivity of amorphous alloys in $\mathrm{Al}-\mathrm{Si}$ ( or Ge)-transition metal systems. Journal of Materials Science. 1988;23(10):3640-3647.

193.Antonowicz J. Phase separation and nanocrystal formation in Al-based metallic glasses. Journal of Alloys and Compounds. 2007;434-435:126-130.

194.Gangopadhyay AK, Croat TK, Kelton KF. The effect of phase separation on subsequent crystallization in $\mathrm{Al}_{88} \mathrm{Gd}_{6} \mathrm{La}_{2} \mathrm{Ni}_{4}$. Acta Materialia. 2000;48(16):4035-4043.

195.Antonowicz J, Kedzierski M, Jezierska E, Latuch J, Yavari AR, Greer L, et al. Small-angle X-ray scattering from phase-separating amorphous metallic alloys undergoing nanocrystallization. Journal of Alloys and Compounds. 2009;483(1-2):116-119.

196.Antonowicz J. Atomic packing and phase separation in Alrare earth metallic glasses. Journal of Materials Science. 2010;45(18):5040-5044.

197.Tian N, Ohnuma M, Ohkubo T, Hono K. Primary Crystallization of an $\mathrm{Al}_{88} \mathrm{Gd}_{6} \mathrm{Er}_{2} \mathrm{Ni}_{4}$ Metallic Glass. Materials Transactions. 2005; $46(12): 2880-2885$

198. Yang HW, Tong WP, Zhao X, Zuo L, Wang JQ. Identification of true glass transitions in an Al-based metallic glass using temperature modulated differential scanning calorimetry. Journal of Alloys and Compounds. 2009;473(1-2):347-350. 